Atmos. Chem. Phys., 17, 15199-15224, 2017

https://doi.org/10.5194/acp-17-15199-2017

(c) Author(s) 2017. This work is distributed under

the Creative Commons Attribution 3.0 License.

\title{
The Horizontal Ice Nucleation Chamber (HINC): INP measurements at conditions relevant for mixed-phase clouds at the High Altitude Research Station Jungfraujoch
}

\author{
Larissa Lacher $^{1}$, Ulrike Lohmann ${ }^{1}$, Yvonne Boose ${ }^{1, \mathrm{a}}$, Assaf Zipori ${ }^{2, \mathrm{~b}}$, Erik Herrmann ${ }^{3}$, Nicolas Bukowiecki ${ }^{3}$, \\ Martin Steinbacher ${ }^{4}$, and Zamin A. Kanji ${ }^{1}$ \\ ${ }^{1}$ Institute for Atmospheric and Climate Science, ETHZ, Zurich, 8092, Switzerland \\ ${ }^{2}$ Institute for Earth Science, Hebrew University, Jerusalem, 76100, Israel \\ ${ }^{3}$ Laboratory of Atmospheric Chemistry, Paul Scherrer Institute, Villigen, 5232, Switzerland \\ ${ }^{4}$ Empa, Swiss Federal Laboratories for Materials Science and Technology, Duebendorf, 8600, Switzerland \\ a now at: Karlsruhe Institute of Technology (KIT), Institute of Meteorology and Climate Research, \\ Garmisch-Partenkirchen, 82467, Germany \\ ${ }^{b}$ now at: Weizmann Institute of Science, Department of Earth and Planetary Sciences, Rehovot, 7610001, Israel
}

Correspondence: Larissa Lacher (larissa.lacher@env.ethz.ch) and Zamin A. Kanji (zamin.kanji@env.ethz.ch)

Received: 18 May 2017 - Discussion started: 29 May 2017

Revised: 9 November 2017 - Accepted: 10 November 2017 - Published: 22 December 2017

\begin{abstract}
In this work we describe the Horizontal Ice Nucleation Chamber (HINC) as a new instrument to measure ambient ice-nucleating particle (INP) concentrations for conditions relevant to mixed-phase clouds. Laboratory verification and validation experiments confirm the accuracy of the thermodynamic conditions of temperature $(T)$ and relative humidity (RH) in HINC with uncertainties in $T$ of $\pm 0.4 \mathrm{~K}$ and in $\mathrm{RH}$ with respect to water $\left(\mathrm{RH}_{\mathrm{w}}\right)$ of $\pm 1.5 \%$, which translates into an uncertainty in $\mathrm{RH}$ with respect to ice $\left(\mathrm{RH}_{\mathrm{i}}\right)$ of $\pm 3.0 \%$ at $T>235 \mathrm{~K}$. For further validation of HINC as a field instrument, two measurement campaigns were conducted in winters 2015 and 2016 at the High Altitude Research Station Jungfraujoch (JFJ; Switzerland, 3580 ma.s.l.) to sample ambient INPs. During winters 2015 and 2016 the site encountered free-tropospheric conditions 92 and $79 \%$ of the time, respectively. We measured INP concentrations at $242 \mathrm{~K}$ at water-subsaturated conditions $\left(\mathrm{RH}_{\mathrm{w}}=94 \%\right)$, relevant for the formation of ice clouds, and in the watersupersaturated regime $\left(\mathrm{RH}_{\mathrm{w}}=104 \%\right)$ to represent ice formation occurring under mixed-phase cloud conditions. In winters 2015 and 2016 the median INP concentrations at $\mathrm{RH}_{\mathrm{w}}=94 \%$ was below the minimum detectable concentration. At $\mathrm{RH}_{\mathrm{w}}=104 \%$, INP concentrations were an order of magnitude higher, with median concentrations in winter 2015 of 2.8 per standard liter ( $\operatorname{stdL}^{-1}$; normalized to stan-
\end{abstract}

dard $T$ of $273 \mathrm{~K}$ and pressure, $p$, of $1013 \mathrm{hPa}$ ) and $4.7 \mathrm{std} \mathrm{L}^{-1}$ in winter 2016. The measurements are in agreement with previous winter measurements obtained with the Portable Ice Nucleation Chamber (PINC) of $2.2 \mathrm{std} \mathrm{L}^{-1}$ at the same location. During winter 2015, two events caused the INP concentrations at $\mathrm{RH}_{\mathrm{w}}=104 \%$ to significantly increase above the campaign average. First, an increase to $72.1 \mathrm{std} \mathrm{L}^{-1}$ was measured during an event influenced by marine air, arriving at the JFJ from the North Sea and the Norwegian Sea. The contribution from anthropogenic or other sources can thereby not be ruled out. Second, INP concentrations up to 146.2 $\mathrm{std} \mathrm{L}^{-1}$ were observed during a Saharan dust event. To our knowledge this is the first time that a clear enrichment in ambient INP concentration in remote regions of the atmosphere is observed during a time of marine air mass influence, suggesting the importance of marine particles on ice nucleation in the free troposphere. 


\section{Introduction}

Clouds and aerosols continue to cause the largest uncertainty in the current assessment of global climate change (e.g., Boucher et al., 2013). Despite their importance in the Earth's system, fundamental knowledge on cloud formation and evolution is still missing. Clouds containing ice can have a positive or negative effect on the Earth's radiative budget, depending on their micro- and macrophysical properties (Lohmann et al., 2016). Cloud microphysical processes are highly variable depending on the available amount of water vapor and the presence of supercooled cloud droplets and ice crystals. In addition, cloud microphysical processes can change during the development of a cloud, and the first formation of ice in clouds is still not completely understood.

Different processes leading to ice formation from the vapor or liquid phase are possible. In the absence of icenucleating particles (INPs) (Pruppacher and Klett, 1997; Lohmann et al., 2016) freezing of supercooled droplets occurs homogeneously, which is relevant in pristine atmospheric environments. It requires temperatures $T<235 \mathrm{~K}$ and a relative humidity $(\mathrm{RH})$ with respect to ice $\left(\mathrm{RH}_{\mathrm{i}}\right)>$ $140 \%$ where the nucleation rate is high enough to outcompete heterogeneous nucleation. In the presence of INPs, heterogeneous ice nucleation is favored, since the particles can lower the energy barrier of the phase change. This freezing pathway is dominant in the mixed-phase cloud regime at $T>235 \mathrm{~K}$, where ice and supercooled water can co-exist and homogeneous freezing rates are negligible. Currently, four different heterogeneous freezing mechanisms are distinguished: deposition nucleation, contact freezing, immersion freezing and condensation freezing (for a detailed description see Vali et al., 2015). Deposition nucleation is relevant for the formation of cirrus clouds as inferred by Cziczo et al. (2013) but is typically not relevant for the formation of mixed-phase clouds, as lidar observations show that the liquid phase is present before ice crystals form (Ansmann et al., 2008). The two most likely freezing modes in mixed-phase clouds are immersion and condensation freezing, where the INP initiates the freezing from within a supercooled droplet. At present it is questioned whether there is a physical difference between immersion and condensation freezing (Welti et al., 2014; Wex et al., 2014; Burkert-Kohn et al., 2017) but, as the ice germ should form from the liquid phase in both cases, it is not expected so.

In addition to different possible ice formation pathways, the identification of ambient INPs remains challenging, since only a small fraction of aerosol particles $\left(\sim 1\right.$ out of $\left.10^{5}\right)$ nucleates ice (Rogers et al., 1998; DeMott et al., 2010), and the exact properties rendering them ice active are not known. INPs can be solid and water insoluble or soluble and crystalline (Kanji et al., 2017), and their ice nucleation ability has been linked to a crystal lattice match to ice, surface defects which increase the density of adsorbed water molecules locally or functional groups which increase the chemical affin- ity to ice via hydrogen bonds (Pruppacher and Klett, 1997). From the large variety of ambient aerosol classes (Kanji et al., 2017), mineral dust particles were observed to nucleate ice efficiently (Hoose and Möhler, 2012, and references therein), and it has been found that K-feldspars are the most efficient INPs out of many tested minerals (Atkinson et al., 2013b; Yakobi-Hancock et al., 2013; Zolles et al., 2015; Harrison et al., 2016; Kaufmann et al., 2016). Furthermore, due to its abundance in the lower free troposphere (FT), it is thought that mineral dust plays a key role in atmospheric ice nucleation (e.g., DeMott et al., 2003a; Kamphus et al., 2010). Particles of biological origin, like certain bacteria, fungal spores and pollen, were found to be efficient INPs at $T>263 \mathrm{~K}$ (Hoose and Möhler, 2012); however, the atmospheric concentration from whole and intact biological particles which are ice active is temporally and spatially variable, and their influence on ice formation is therefore rather seasonal and local in nature (Després et al., 2012). Nanometer scaled fragments from biological particles are present in much higher concentrations and might have atmospheric implications (Pummer et al., 2012; Augustin et al., 2013; O'Sullivan et al., 2015; Fröhlich-Nowoisky et al., 2015; Wilson et al., 2015). Additionally, bacteria have been found in Saharan (Meola et al., 2015) and soil dust (Conen et al., 2011) aerosols, possibly influencing their ice nucleation activity.

The role of marine aerosol as a source of INPs has been reported for the first time more than five decades ago (Brier and Kline, 1959; Cziczo and Froyd, 2014) and has been reemphasized recently and observed in various field and laboratory studies (Cziczo et al., 2013; Knopf et al., 2014; Wilson et al., 2015; DeMott et al., 2016). Recent field studies or studies of field samples in the laboratory (Cziczo et al., 2013; Knopf et al., 2014; Wilson et al., 2015; Ladino et al., 2016; DeMott et al., 2016) have shown that particles and organic matter sampled or emitted from the sea surface can be a source of INPs. Marine aerosols are produced via a bubblebursting mechanism (e.g., de Leeuw et al., 2011; Gantt and Meskhidze, 2013; Aller et al., 2005; Cunliffe et al., 2013) when entrained air bubbles rise through the sea surface microlayer and burst upon contact with the atmosphere. The sea surface microlayer is usually enriched in biogenic material leading to the emission of these in the atmosphere as aerosol particles. A source of these marine particles can be microorganisms like phytoplankton and bacteria, exopolymer secretion, colloidal aggregates, glassy organic aerosols, crystalline hydrated sodium chloride particles and frost flowers (summarized in Burrows et al., 2013). Cells or cell fragments and exudates of phytoplankton species were found to be ice active (Knopf et al., 2011; Alpert et al., 2011; Wilson et al., 2015), and biological material during phytoplankton blooms might also play an important role for ice nucleation (Prather et al., 2013; DeMott et al., 2016). These marine aerosols can be submicrometer in size (e.g., $0.02-0.2 \mu \mathrm{m}$, Wilson et al., 2015; 0.25-1 $\mu \mathrm{m}$, DeLeon-Rodriguez et al., 
2013), a size range which is transported to higher altitudes. Burrows et al. (2013) state that marine biogenic particles are an important source of INPs in remote marine areas in the absence of other efficient INPs such as mineral dust. During airborne measurements, Cziczo et al. (2013) found sea salt in ice residuals from tropical tropopause cirrus clouds, especially over the open ocean but also in reduced concentrations over land.

In addition to laboratory studies, which aim to understand the physical processes of ice nucleation and determine key aspects of aerosols acting as INPs, it is crucial to quantify the total number concentration of ambient INPs in an environment relevant for clouds containing ice and to address the question of their variability in space and time. Several studies exist from airborne platforms (e.g., Bigg, 1967; Rogers et al., 1998; Prenni et al., 2009; DeMott et al., 2010; Avramov et al., 2011; Schrod et al., 2017) and ground-based observations (e.g., DeMott et al., 2003b; Chou et al., 2011; Ardon-Dryer and Levin, 2014; Mason et al., 2016; Boose et al., 2016a, b) quantifying the number concentration of INPs and identifying their potential sources. Typically, filter sampling with subsequent offline freezing methods, and online measurements with continuous-flow-diffusion chambers (CFDCs) are used as INP measurement techniques. For filter sampling, aerosols are collected for a certain time and known air volume, after which the collected particulate is cooled and exposed to controlled temperature and RH conditions (e.g., Bigg, 1967; Santachiara et al., 2010; Conen et al., 2011; Bingemer et al., 2012; Ardon-Dryer and Levin, 2014; Knopf et al., 2014; Mason et al., 2015). Filter techniques observe the onset freezing temperature of a sample with a very large number of particles resulting in a very sensitive detection limit. However, this comes at the cost of a low temporal resolution since the sampling times of the filters often are on the order of a few hours or longer. CFDCs measure INP concentrations in real time with a higher temporal resolution, on the order of a few to tens of minutes (e.g., Rogers, 1988; Rogers et al., 2001; Chou et al., 2011), but their total sampling volume is lower, and their sensitivity to detect INPs is limited at low concentrations (Boose et al., 2016a). This in particular is challenging at low supercooling or in areas where INP concentrations are lower than $0.1-1$ per standard liter ( std $^{-1}$; normalized to standard $T$ of $273 \mathrm{~K}$ and pressure, $p$, of $1013 \mathrm{hPa}$ ).

Measurements of INP concentrations are rare during different seasons in an environment which is relevant for the formation of mixed-phase clouds. Conen et al. (2015) collected filters at different elevations in the (partly) FT, namely at Mt. Chaumont and at the Jungfraujoch (JFJ) in Switzerland (1171 and $3580 \mathrm{~m}$, respectively) and at the Izaña observatory on Tenerife, Canary Islands $(2373 \mathrm{~m})$. They sampled for 1 year with one sample representing $24 \mathrm{~h}$, and INP measurements were reported for the temperature range of 265 to $269 \mathrm{~K}$. At the JFJ, and for the same temperature range, they found a seasonal cycle with INP concentrations ranging from
0.001 to $0.01 \mathrm{std}^{-1}$, with a maximum in summer and a minimum in winter. This variation is attributed to previous INP activation and subsequent fallout from advected air masses prior to reaching the JFJ, leaving an air mass which is depleted in INPs upon arrival to the JFJ during wintertime (Conen et al., 2015; Stopelli et al., 2015). Also at the JFJ, INP measurements were performed at $T=241 \mathrm{~K}$ during winters 2012, 2013 and 2014 with the CFDC Portable Ice Nucleation Chamber (PINC; Boose et al., 2016a). INP concentrations were sampled in the deposition nucleation mode in winters 2012-2014 and also in the condensation freezing mode in winter 2014. Median INP concentrations below (above) water saturation were in the range of $\leq 0.05-0.1$ (4.2) $\mathrm{std} \mathrm{L}^{-1}$. To extend these measurements and to establish a longer time series of measurements at the JFJ, INP concentrations are measured since summer 2014 at the same temperature and RH conditions, with the newly built Horizontal Ice Nucleation Chamber (HINC) based on the design of Kanji and Abbatt (2009). In this study, the new chamber is characterized to be used as a field instrument. To complement the validation and verification experiments performed in the laboratory, two field campaigns in winters 2015 and 2016 were performed, and results are compared to previous winter measurements from the same location discussed in Boose et al. (2016a). In addition, two events of anomalously high INP concentrations from the winter 2015 campaign are discussed to investigate the origin of these INPs.

\section{Ice nucleation measurements}

\subsection{Technical description}

HINC is a CFDC, based on the design of the UT-CFDC (Kanji and Abbatt, 2009). A schematic of HINC is shown in Fig. 1, including the outer dimensions of the chamber. Inner dimensions and more detailed design aspects can be found in Kanji and Abbatt (2009). HINC consists of two horizontally oriented copper plates which are cooled by an external recirculating ethanol cooler (LAUDA, RP 890 C). Self-adhering glass fiber filter papers (PALL 66217) mounted on the inner walls of the chamber are wetted prior to an experiment to create an ice layer upon cooling the walls. For the wetting procedure, the walls are kept at room temperature and the chamber is tilted to an angle of $45^{\circ}$, and approximately $100 \mathrm{~mL}$ of double-deionized water is used to wet the filter papers via four water ports, which are in contact with the filter papers of the upper and lower walls. The chamber is kept in this position for $30 \mathrm{~min}$ to drain excess water via the outlet port downstream of the chamber. After draining, the chamber is brought back into a horizontal position and the outlet port is dried to ensure no residual water drops are retained. Following the wetting procedure, an optical particle counter (OPC; MetOne, GT-526S) is attached to the outlet port, and the walls are cooled down to the desired set point tempera- 
ture $<273 \mathrm{~K}$. To establish a $\mathrm{RH}_{\mathrm{i}}$ and $\mathrm{RH}_{\mathrm{w}}>100 \%$, a temperature gradient $\Delta T$ is applied between the two ice coated walls (both walls below $273 \mathrm{~K}$ ), with the upper wall set to the warmer temperature. The horizontal orientation of the chamber ensures no internal convection. For an experiment where the RH should be increased, which is typical to determine the onset RH of INPs, the $\Delta T$ is achieved by a temperature increase and decrease of the respective walls at equal rates. This ensures that the temperature in the center, where the air containing the aerosols is injected, remains constant. Aerosol particles enter the chamber via a movable injector and are released into the chamber via a slit in the front of the injector. The cross section area of the slit is smaller than the cross section of the inner diameter on the injector, which creates a small overpressure at the particles exiting through the slit promoting an equal distribution of the aerosols over the width of the slit. The outer diameter of the injector is $6.35 \mathrm{~mm}$ (inner diameter $3.175 \mathrm{~mm}$ ), which ensures that at a flow rate of $2.8 \mathrm{std} \mathrm{Lmin}^{-1}$, and at $242 \mathrm{~K}$ the turbulence regime is not encountered by air flowing over the aerosol injector (Reynolds number 880, well below the threshold of 2000 for turbulent flow). Furthermore, given the chamber dimensions, before and after the injector, the Reynolds number is 66, well below the critical number. It is expected that the minor disturbances in the flow by the injector will not result in transitioning from the laminar to turbulent regime. The center flow containing the aerosols (aerosol flow) is layered in between a dry particle-free sheath nitrogen (purity 5.0, $99.999 \%, \mathrm{H}_{2} \mathrm{O} \leq 3 \mathrm{ppm}$ ) flow, with a sheath-to-aerosol flow ratio of typically $12: 1$, which ensures the aerosol flow remains laminar and is exposed to the constant center temperature and RH conditions in the chamber. The sheath air is controlled by a mass flow controller (MFC; MKS, MF1, full scale flow of $5 \mathrm{std} \mathrm{L} \mathrm{min}^{-1}$ ). The position of the injector thereby determines the residence time of the aerosols in the chamber. Within this residence time ice crystals may nucleate on aerosol particles and grow to larger sizes, allowing for discrimination by size with the OPC. For the field measurements reported here, particles detected by the OPC in size bin $>5 \mu \mathrm{m}$ in diameter are classified as ice (see Sect. 2.2.3). Counts in smaller size channels could be contaminated by unactivated aerosol particles and, at water-saturated conditions, the size bins up to $3-4 \mu \mathrm{m}$ could be contaminated by droplets. For measurements reported here, HINC was kept at sufficiently low RH to ensure that water droplets did not contaminate the signal in the $>5 \mu \mathrm{m}$ channel. The OPC is calibrated for a total flow of $2.8 \mathrm{std} \mathrm{L} \mathrm{min}^{-1}$, which is set by an external pump. The MFC is used to set the $92 \%$ sheath air flow, so that the remaining $8 \%$ is made up by the aerosol flow sampled (pulled) into the chamber.

LabVIEW $^{\circledR}$ is used to control the recirculating cooler temperature and resulting $\mathrm{RH}$ in the chamber by regulating the cold and warm wall temperatures. Integrated into the LabVIEW $^{\circledR}$ control panel are the flow rate of the sheath flow through the MFC and a motorised valve to direct the aerosol flow through a HEPA filter to quantify the noise for the signal-to-noise ratio (see Sect. 2.3). Additionally, the counts in all size bins of the OPC are read out, and all set and output parameters are logged into a single file which is later used for data analysis.

\subsection{HINC validation and verification}

Here we present laboratory measurements, using a variety of aerosol particles, to verify the accuracy in $T$ and RH for the newly built INP counter. We define the operational range, where it reliably measures INPs in the water-saturated regime. To confirm these operation settings in the field, additional tests with ambient particles at the JFJ were performed.

\subsubsection{Sample preparation}

To validate the temperature and RH conditions in HINC, hygroscopic growth upon deliquescence, cloud droplet activation and homogeneous freezing experiments with sizeselected ammonium sulfate $\left(\left(\mathrm{NH}_{4}\right)_{2} \mathrm{SO}_{4}\right)$, sodium chloride $(\mathrm{NaCl})$ and sulfuric acid $\left(\mathrm{H}_{2} \mathrm{SO}_{4}\right)$ particles were conducted, as well as experiments with polydisperse ambient particles in the field. Except for the latter, particles were generated as aqueous solutions $\left(0.05625 \% \mathrm{w} / \mathrm{w}\right.$ for $\left(\mathrm{NH}_{4}\right)_{2} \mathrm{SO}_{4}$, $5 \% w / w$ for $\mathrm{NaCl}, 60 \% w / w$ for $\mathrm{H}_{2} \mathrm{SO}_{4}$ ), atomized and dried by diffusion to $\mathrm{RH}_{\mathrm{w}}<2 \%$, before they were size selected by a differential mobility analyzer (DMA; TSI, 3081). For the deliquescence and cloud droplet activation experiments, $200 \mathrm{~nm}$ particles were used, and for homogeneous freezing experiments $100 \mathrm{~nm} \mathrm{H}_{2} \mathrm{SO}_{4}$ particles were used. Results from these experiments are presented for different size channels, which show the growth of the particles at different RHs to various sizes. For example, for the homogeneous freezing experiments at $233 \mathrm{~K}$, ice particles are observed in size channels $>0.5 \mu \mathrm{m}$ at $\mathrm{RH}_{\mathrm{w}}>97.5 \%$, while in the experiments at $242 / 243 \mathrm{~K}$ and at $\mathrm{RH}_{\mathrm{w}}=100-107 \%$ cloud droplets are measured in size channels $<5 \mu \mathrm{m}$, but not in the size channel $>5 \mu \mathrm{m}$, which is thus used to detect ice crystals. The activated fraction (AF), which is the ratio of aerosol particles activated into cloud droplets or nucleated ice crystals to the number of total particles, counted by a condensation particle counter (CPC; TSI 3772) in parallel, is reported.

\subsubsection{Accuracy of temperature and RH in HINC}

At $T<235 \mathrm{~K}$, homogeneous freezing experiments were conducted to compare the onset of freezing observed in HINC to values reported and modeled in the literature (Koop et al., 2000a). In the respective experiments the $\mathrm{RH}_{\mathrm{w}}$ conditions in HINC were increased at an approximate rate of $0.5 \% \mathrm{~min}^{-1}$, so that an increase in $\mathrm{RH}_{\mathrm{w}}$ of $\sim 10 \%$ was achieved over a total time of $20 \mathrm{~min}$, which implies that during the $8 \mathrm{~s}$ aerosol residence time in HINC the particles experienced constant $\mathrm{RH}$ conditions. Experiments with $100 \mathrm{~nm} \mathrm{H}_{2} \mathrm{SO}_{4}$ particles at $233 \mathrm{~K}$ (Fig. 2) revealed that the onset of freezing in HINC 


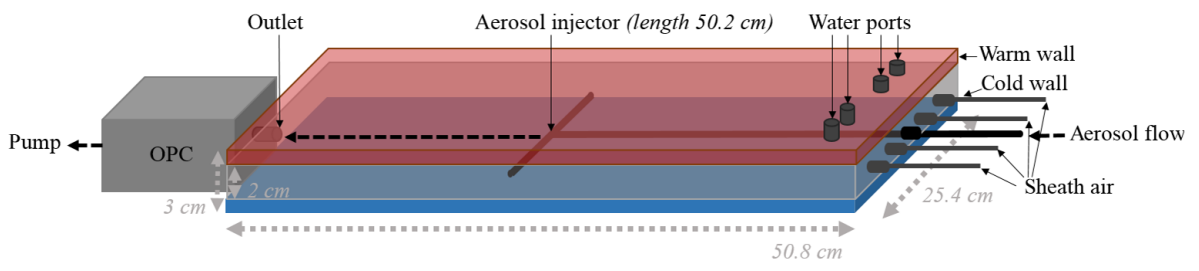

Figure 1. Schematic and outer dimensions of HINC (main chamber).

occurs within $\mathrm{RH}_{\mathrm{w}} \pm 1.5 \%$ of the expected $\mathrm{RH}_{\mathrm{w}}$ required to freeze solution droplets of the same initial dry size of the solute particles (Koop et al., 2000a), based on a fixed nucleation rate coefficient of $10^{10} \mathrm{~cm}^{-3} \mathrm{~s}^{-1}$ (Koop et al., 2000a), which is $\mathrm{RH}_{\mathrm{w}}=98.6 \%$ as shown by the dashed line in Fig. 2. The reported $\mathrm{RH}_{\mathrm{w}}$ on the $x$ axis in the figure represents the nominal conditions at the centerline of the chamber, which is the center of the aerosol layer. Due to the width of the aerosol layer, the particles are exposed to a variation in $\mathrm{RH}_{\mathrm{w}} \pm 1 \%$ and to an uncertainty in $\mathrm{RH}_{\mathrm{w}} \pm 1 \%$ due to the temperature uncertainty. The grey shading in Fig. 2 represents this total calculated uncertainty of $\mathrm{RH}_{\mathrm{w}} \pm 2 \%$, for a prescribed $\mathrm{RH}_{\mathrm{w}}=98.6 \%$. When the chamber is set to $\mathrm{RH}_{\mathrm{w}}=98.6 \%$, the aerosols can be exposed to the $\mathrm{RH}_{\mathrm{w}}$ range of 96.6$100.6 \%$. Our experiments reveal an increase in the AF of particles between 2 and $8 \mu \mathrm{m}$, starting at $97.5 \%$ and reaching a plateau value at $99.5 \%$, which is in agreement to the expected range of freezing within the aerosol layer. According to theoretical calculations (Koop et al., 2000a) at $233 \mathrm{~K}$ and $\mathrm{RH}_{\mathrm{w}}=98.6 \%(99 \%)$ and using a nucleation rate of $10^{10}$ $\mathrm{cm}^{-3} \mathrm{~s}^{-1}$, we expect for initial $100 \mathrm{~nm} \mathrm{H}_{2} \mathrm{SO}_{4}$ particles at a residence time of $8 \mathrm{~s}$ an $\mathrm{AF}$ of 0.001 (0.005), which is an order of magnitude below the AFs observed in Fig. 2. However, this $\mathrm{AF}$ is within the uncertainty range given that in this region where the $\mathrm{AF}$ is a steep function of $\mathrm{RH}$, an uncertainty of $\mathrm{RH}_{\mathrm{w}}$ of $1 \%$ can result in a change in $\mathrm{AF}$ by a factor of $10-100$.

Above homogeneous freezing temperatures $(T>235 \mathrm{~K})$, we expect cloud droplet activation for $200 \mathrm{~nm}\left(\mathrm{NH}_{4}\right)_{2} \mathrm{SO}_{4}$ and $\mathrm{H}_{2} \mathrm{SO}_{4}$ particles at $\mathrm{RH}_{\mathrm{w}}=100 \%$. We thereby report the onset of cloud droplet formation, which is the first observed increase in the $\mathrm{AF}$ at a given size in the OPC channels. This is observed in the smaller OPC channels $(0.5-2 \mu \mathrm{m})$ as an increase in the $\mathrm{AF}$ when the conditions in the chamber approach $\mathrm{RH}_{\mathrm{w}}=99-100 \%$ as observed for $\mathrm{H}_{2} \mathrm{SO}_{4}$ (Fig. 3) and for ambient particles (Fig. 4). The grey shaded area in Figs. 3, 4 and 5 also includes the calculated variation and uncertainty in $\mathrm{RH}_{\mathrm{w}}$ for the given temperatures of 242 and $243 \mathrm{~K}$, respectively. As discussed above, the exposure of the aerosol particles to this variable RH leads to droplet activation not only at $\mathrm{RH}=100 \%$ but in a range of $\mathrm{RH}$ pertaining to the variation and uncertainty in HINC. Such aerosol particles grow within the residence time of $8 \mathrm{~s}$ to different sizes, which is depicted by the difference in the OPC size channels. In addition, this is also the reason why at $\mathrm{RH}_{\mathrm{w}}=101 \%$ for example (Fig. 3), the AF is still observed to be increasing because some particles in the aerosol layer are still exposed to $\mathrm{RH}_{\mathrm{w}}=99-100 \%$, explaining why droplet activation is observed up to a $\mathrm{RH}_{\mathrm{w}}$ of $102 \%$. We note that an increase in the AF of initial $200 \mathrm{~nm} \mathrm{H}_{2} \mathrm{SO}_{4}$ is observed prior to $\mathrm{RH}_{\mathrm{w}}=100 \%$ in the 0.5 and $1 \mu \mathrm{m}$ channels (Fig. 3), which is to be expected due to hygroscopic growth of the $\mathrm{H}_{2} \mathrm{SO}_{4}$ particles. Therefore, the increase in size for $\mathrm{RH}_{\mathrm{w}}<100 \%$ is only observed in the smaller size channels occurring prior to droplet activation at $\mathrm{RH}_{\mathrm{w}}<100 \%$, while an increase at $\mathrm{RH}_{\mathrm{w}}=100 \%$ in the $>2 \mu \mathrm{m}$ channel is observed due to cloud droplet activation. In contrast, the ambient particles show droplet activation in the $>0.5 \mu \mathrm{m},>1 \mu \mathrm{m}$ and $>2 \mu \mathrm{m}$ channels at $\mathrm{RH}_{\mathrm{w}}=101.5 \%$ (Fig. 4). This is likely due to the lower hygroscopicity of the ambient particles compared to $\mathrm{H}_{2} \mathrm{SO}_{4}$ and due to a larger fraction of the sampled ambient particles being $\ll 100 \mathrm{~nm}$, requiring higher $\mathrm{RH}$ for the droplets to activate and grow to detectable cloud droplet sizes at this temperature. In addition, the experiments could also be influenced by RH uncertainties (see Sect. 2.3).

At lower $\mathrm{RH}_{\mathrm{w}}$, hygroscopic growth due to deliquescence was also observed as an increase in particle concentrations in the smallest OPC channels of 0.3 and $1 \mu \mathrm{m}$, which occurred for $200 \mathrm{~nm} \mathrm{NaCl}$ in the range of $\mathrm{RH}_{\mathrm{w}}=79.5-81 \%$ (Fig. 5). The observed increase in the particle fraction due to deliquescence and hygroscopic growth compares well to literature results reported to be $\mathrm{RH}_{\mathrm{w}}=77 \pm 2.5 \%$ (Koop et al., $2000 \mathrm{~b}$ ). We observe a first strong increase in the particle fraction $>0.3$ and $>1 \mu \mathrm{m}$ at $80-81 \%$, followed by a gradual increase in the particle fraction to unity (within uncertainties) at $\mathrm{RH}_{\mathrm{w}} \approx 94 \%$ for the $>0.3 \mu \mathrm{m}$ trace. Deliquescence is a phase change and not a growth process, and a delay as compared to the literature value (dashed line Fig. 5) is expected, since the deliquesced particles need to grow to a size $>0.3 \mu \mathrm{m}$ to be detected in the OPC. In theory we would expect all particles to grow to sizes larger than $0.3 \mu \mathrm{m}$ at $\mathrm{RH}_{\mathrm{w}} \geq 80 \%$ since the deliquescence and growth threshold has been reached. However, we note that due to an uncertainty in sizing of up to $3.5 \%$ in the DMA, particles between 193 and $207 \mathrm{~nm}$ for a nominal size of $200 \mathrm{~nm}$ will be sampled. In reality, we expect an even broader size distribution because dried $\mathrm{NaCl}$ particles are aspherical and result in larger sizing errors (Ardon-Dryer et al., 2015). Due to the size selection method with the DMA, a non-negligible fraction of larger particles (10\%) between 320 and $440 \mathrm{~nm}$ (from 


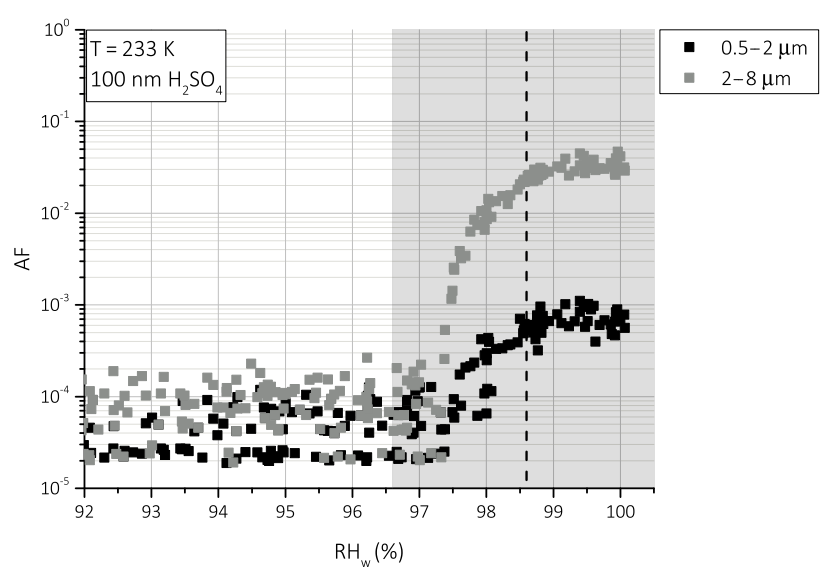

Figure 2. Homogeneous freezing curve of $100 \mathrm{~nm}$ dry diameter $\mathrm{H}_{2} \mathrm{SO}_{4}$ particles. $\mathrm{AF}$ as a function of $\mathrm{RH}_{\mathrm{w}}$ at $233 \mathrm{~K}$ in the OPC size channels $0.5-2 \mu \mathrm{m}$ (dark grey) and $2-8 \mu \mathrm{m}$ (light grey). The dashed line $\left(\mathrm{RH}_{\mathrm{W}}=98.6 \%\right)$ represents the expected $\mathrm{RH}_{\mathrm{W}}$ for homogeneous freezing of dilute solution drops of an initial dry diameter of $100 \mathrm{~nm}$ (Koop et al., 2000a), and the shaded region indicates the calculated range of $\mathrm{RH}_{\mathrm{w}}$ and uncertainty to which the particles in the aerosol layer in HINC are exposed.

double and triple charged particles) will also be sampled by HINC. This breadth in size distribution may explain the initial increase in particle fraction at $\mathrm{RH}_{\mathrm{w}}=80 \%$ arising from the multiply charged particles followed by a progressive increase in the particle fraction up to $\mathrm{RH}_{\mathrm{w}}=94 \%$ where all the particles grow to sizes $>0.3 \mu \mathrm{m}$. The same can be said for the $>1 \mu \mathrm{m}$ trace. Note that complete activation in this trace occurs at $\mathrm{RH}_{\mathrm{w}}>100 \%$, which is expected from the variation in RH in the aerosol layer. Finally, we note that the goal of this experiment is to demonstrate that HINC can achieve prescribed $\mathrm{RH}$ conditions with reasonable accuracy by controlling the wall temperature as is seen by the onset in growth at $\mathrm{RH}_{\mathrm{w}}=80 \%$ in Fig. 5. Additionally, we acknowledge that the fraction of particles $>0.3 \mu \mathrm{m}$ reaches a maximum at higher $\mathrm{RH}_{\mathrm{w}}$ than theoretically expected, which can also be attributed to the sizing and counting uncertainty of the OPC, which is most pronounced at these small particle sizes, when the wavelength of the laser $(780 \mathrm{~nm})$ is similar to the diameter of detectable particles. Due to the generation method of $\mathrm{NaCl}$ at $T>273 \mathrm{~K}$ and immediate exposure of the $\mathrm{NaCl}$ to the respective temperature and humidity when the aerosol particles are injected in HINC, we believe that we deliquesce $\mathrm{NaCl}$ anhydrate and not $\mathrm{NaCl}$ dihydrate (Bode et al., 2015). For $200 \mathrm{~nm}\left(\mathrm{NH}_{4}\right)_{2} \mathrm{SO}_{4}$ particles, deliquescence and hygroscopic growth was also observed at $\mathrm{RH}_{\mathrm{w}}=82-85 \%$, consistent with the $\left(\mathrm{NH}_{4}\right)_{2} \mathrm{SO}_{4}$ deliquescence at a $\mathrm{RH}_{\mathrm{w}}=82$ $84 \%$ (Cziczo and Abbatt, 1999). All validation experiments to verify the RH and temperature accuracy in HINC are summarized in Fig. 6.

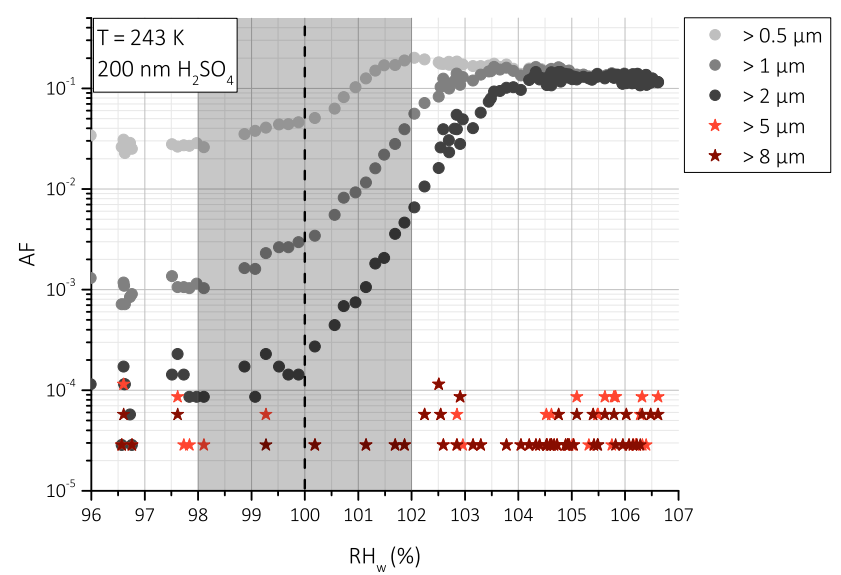

Figure 3. Water droplet (or ice crystal for $>5 \mu \mathrm{m}$ ) activation fraction and subsequent growth as function of $\mathrm{RH}_{\mathrm{W}}$ at $243 \mathrm{~K}$ for $200 \mathrm{~nm}$ dry diameter $\mathrm{H}_{2} \mathrm{SO}_{4}$ particles, shown for all size channels $>0.5 \mu \mathrm{m}$ in the OPC. Vertical dashed line represents expected onset for cloud droplet formation; grey area refers to the calculated variation and uncertainty of RH in the aerosol layer.

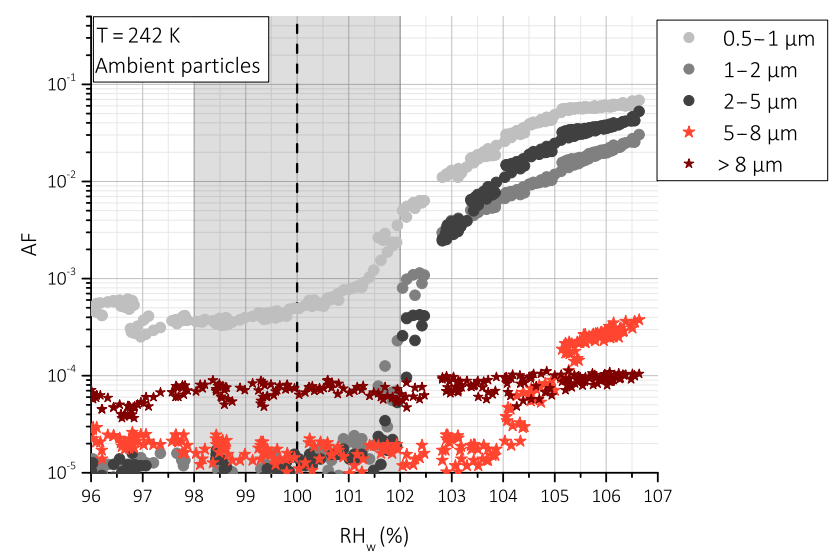

Figure 4. Water droplet activation fraction and subsequent growth as function of $\mathrm{RH}_{\mathrm{W}}$ at $242 \mathrm{~K}$ for ambient polydisperse particles sampled at the JFJ, shown for all size channels in the OPC. Vertical dashed line represents expected onset for cloud droplet formation; grey area refers to the calculated variation and uncertainty of RH in the aerosol layer.

\subsubsection{Upper RH limit for ice crystal detection: water drop survival (WDS)}

The upper RH achievable to reliably detect ice crystals is limited by the possible activation and subsequent diffusional growth of water drops, since only the optical size is used to discriminate between ice crystals (larger) and water droplets (smaller) at the same temperature and RH conditions. To identify the maximum operation $\mathrm{RH}$, experiments are conducted with $200 \mathrm{~nm}\left(\mathrm{NH}_{4}\right)_{2} \mathrm{SO}_{4}$ and $\mathrm{H}_{2} \mathrm{SO}_{4}$ particles at $T>235 \mathrm{~K}$ where homogeneous freezing is insignificant. For these experiments the RH is increased until acti- 


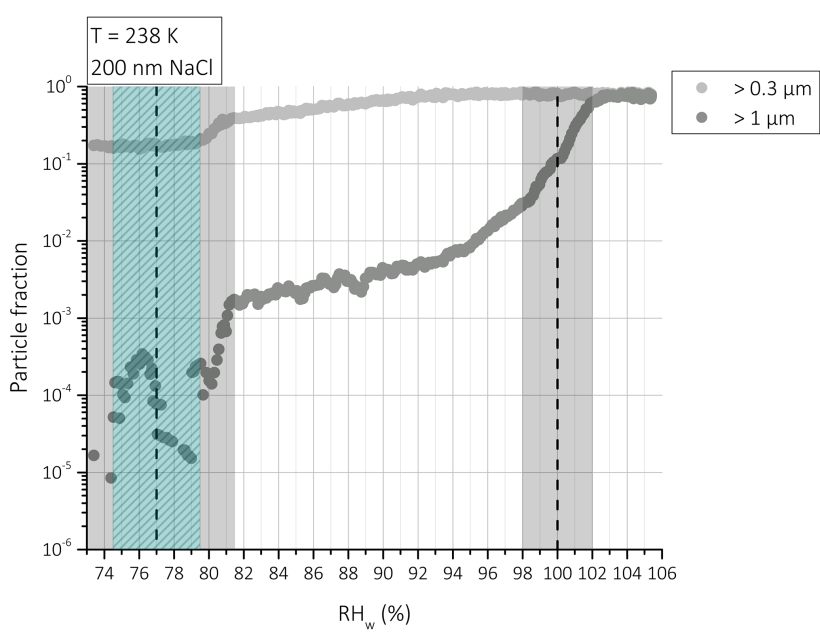

Figure 5. Particle fraction due to hygroscopic growth after deliquescence as function of $\mathrm{RH}_{\mathrm{W}}$ at $238 \mathrm{~K}$ for $200 \mathrm{~nm} \mathrm{NaCl}$ particles. Vertical dashed lines represent deliquescence $\mathrm{RH}_{\mathrm{W}}$ of $\mathrm{NaCl}$ at $\mathrm{RH}_{\mathrm{W}}=77 \%$ and onset of cloud droplet formation at $\mathrm{RH}_{\mathrm{W}}=$ $100 \%$; green shaded area refers to observed uncertainty in deliquescence by Koop et al. (2000b); grey area refers to the calculated variation and uncertainty of RH in HINC in the aerosol layer.

vated water droplets grow to a diameter which is detected in the OPC size channel used to detect ice crystals. This is referred to as the WDS point. Based on diffusional growth calculations (Rogers and Yau, 1989) activated cloud droplets of an initial diameter of $200 \mathrm{~nm}$ can grow to a size of $4 \mu \mathrm{m}$ in $\mathrm{HINC}$ at $242 \mathrm{~K}$, with $\mathrm{RH}_{\mathrm{w}}=104 \%$ for a residence time of $8 \mathrm{~s}$ (conditions used for field experiments reported here), giving us confidence that droplets are not detected in the $>5 \mu \mathrm{m}$ channel. Only at a $\mathrm{RH}_{\mathrm{w}}$ of $107 \%$ can cloud droplets grow to $>5 \mu \mathrm{m}$, and therefore by conducting our experiments at $\mathrm{RH}_{\mathrm{w}}=104 \%$ we only detect ice crystals in the $5 \mu \mathrm{m}$ OPC channel. As a confirmation, no counts in the size channel $>5 \mu \mathrm{m}$ were observed for $\mathrm{H}_{2} \mathrm{SO}_{4}$ particles (Fig. 3) even up to a $\mathrm{RH}_{\mathrm{w}}$ of $107 \%$. With sampling ambient particles an increase in AF for particles $>5 \mu \mathrm{m}$ at $\mathrm{RH}_{\mathrm{w}}=104$ $105 \%$ is observed (see Fig. 4), which can be caused by ice crystals forming heterogeneously, since water droplets cannot grow to this size at the respective conditions in HINC. These calculations also reveal that the diffusional growth of the activated cloud droplets and hence the final size of the cloud droplets of interest, which is $5 \mu \mathrm{m}$ for the discussed field experiments, are insensitive to the initial dry diameter of the aerosol particles, since the final droplet size at $242 \mathrm{~K}$, $\mathrm{RH}_{\mathrm{w}}=104 \%$ and a residence time of $8 \mathrm{~s}$ of an initial 50, 200 and $800 \mathrm{~nm}$ is $4.035,4.038$ and $4.08 \mu \mathrm{m}$, respectively. Also, effects of the particle chemistry are assumed to be negligible for the droplet activation, since we conduct our experiments at $\mathrm{RH}_{\mathrm{w}} \geq 104 \%$, where a variety of aerosol chemical compositions should activate into droplets. Thus water droplets contaminating the $5 \mu \mathrm{m}$ channel should not occur even with varying hygroscopicities and sizes of aerosol populations. Note that the AF even at low RH is non-zero, which is caused by either unactivated sample particles (particularly in the smallest size channels) or internal background counts (see Sect. 2.3). These experiments give us confidence that by operating at $T=242 \mathrm{~K}$ and an $\mathrm{RH}_{\mathrm{w}} \leq 104 \%$, the OPC size channel $>5 \mu \mathrm{m}$ is suited to reliably detect ice crystals for field measurements. Diffusional growth of ice crystals for the respective conditions in HINC reveals that ice crystals can be lost to settling within $7 \mathrm{~s}$. Still, residence time experiments with $400 \mathrm{~nm}$ microcline particles at $242 \mathrm{~K}$ and $\mathrm{RH}_{\mathrm{w}}=104 \%$ show that the AF is at a maximum value at $8 \mathrm{~s}$ (Fig. A1, Appendix), which informed the $8 \mathrm{~s}$ residence time in the field experiments. This discrepancy with the theoretical calculation of $7 \mathrm{~s}$ is expected due to assumptions in the diffusional growth calculations, such as immediate activation upon entering the chamber and assuming spherical ice crystals. The residence time of $8 \mathrm{~s}$ therefore should include consideration for the equilibration time of the particles to the center supersaturation $(\sim 0.2 \mathrm{~s})$, the growth time of ice crystals to $>5 \mu \mathrm{m}$ $(2 \mathrm{~s})$ and time dependence for nucleation (up to $\sim 6 \mathrm{~s}$ ). Thus the residence time of $8 \mathrm{~s}$ should also minimize the number of ice crystals $<5 \mu \mathrm{m}$, since ice crystals only need $2 \mathrm{~s}$ to grow by diffusion to sizes $>5 \mu \mathrm{m}$ at this high $\mathrm{RH}_{\mathrm{i}}=140 \%$ $\left(\mathrm{RH}_{\mathrm{w}}=104 \%\right)$. We believe that undercounting INPs due to ice crystals $<5 \mu \mathrm{m}$ should not significantly influence the INP concentrations reported especially given the day-to-day variability in INP concentrations found at the field site studied in this work.

\subsubsection{Summary of validation and verification experiments}

In Fig. 6, we show the results from all the validation experiments performed. The observed phase changes are in the expected range of homogeneous freezing of solution droplets (Koop et al., 2000a), cloud droplet formation (Lohmann et al., 2016) and deliquescence of $\mathrm{NaCl}$ (Koop et al., 2000b) and $\left(\mathrm{NH}_{4}\right)_{2} \mathrm{SO}_{4}$ (Cziczo and Abbatt, 1999). The ice onset for homogeneous freezing of $\mathrm{H}_{2} \mathrm{SO}_{4}$ was observed within a range of $\mathrm{RH}_{\mathrm{w}} \pm 1.5 \%$ of the value reported in Koop et al. (2000a). At colder temperatures, the onset of homogeneous freezing is observed to shift to higher $\mathrm{RH}_{\mathrm{w}}$ but still remains well within the range of uncertainty in $\mathrm{RH}$ (see Sect. 2.3) of HINC. Above $235 \mathrm{~K}$, where freezing of dilute water droplets is not expected, droplet formation for both $\mathrm{H}_{2} \mathrm{SO}_{4}$ and $\left(\mathrm{NH}_{4}\right)_{2} \mathrm{SO}_{4}$ as well as ambient particles was observed at $\mathrm{RH}_{\mathrm{w}}=100 \pm 1.5 \%$, where particles initially not detectable in the OPC size channel $>1 \mu \mathrm{m}$ activate to droplets and grow large enough to be detected. At lower $\mathrm{RH}_{\mathrm{w}}$ we observe hygroscopic growth upon deliquescence of $\mathrm{NaCl}$ and $\left(\mathrm{NH}_{4}\right)_{2} \mathrm{SO}_{4}$ particles as an increase in the OPC size channel $>0.3 \mu \mathrm{m}$. For $\mathrm{NaCl}$ such an increase was observed at $\mathrm{RH}_{\mathrm{w}}=79-81 \%$, as compared to a $\mathrm{RH}_{\mathrm{w}}=77 \pm 2.5 \%$ (Koop et al., 2000b). For $\left(\mathrm{NH}_{4}\right)_{2} \mathrm{SO}_{4}$ 


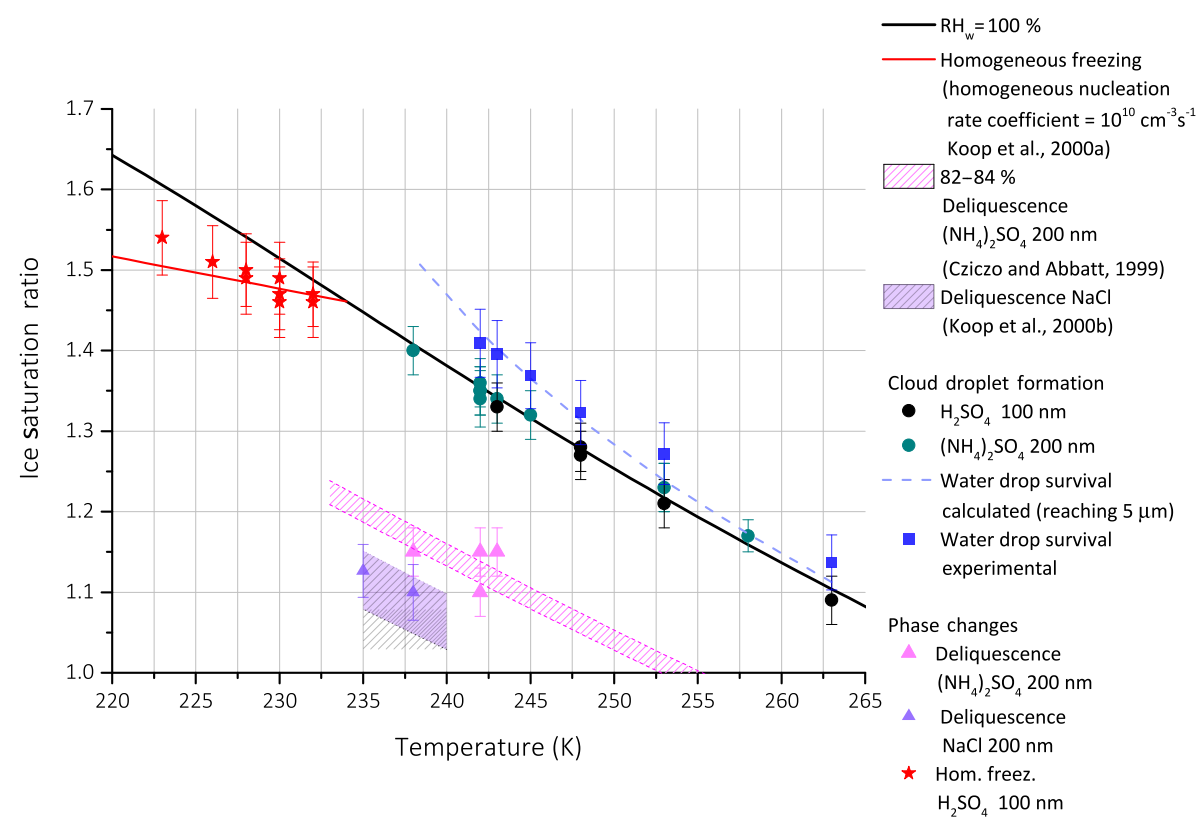

Figure 6. Summary of characterization experiments and comparison to literature and theoretical values of phase changes and growth processes. Data from experiments reflect the first appearance of ice (ice onset) when the AF increases above the chamber background levels.

particles a growth was observed at $\mathrm{RH}_{\mathrm{w}}=81-85 \%$ as compared to $\mathrm{RH}_{\mathrm{w}}=82-84 \%$ (Cziczo and Abbatt, 1999). Both the phase change and cloud droplet formation experiments with $\mathrm{H}_{2} \mathrm{SO}_{4},\left(\mathrm{NH}_{4}\right)_{2} \mathrm{SO}_{4}, \mathrm{NaCl}$ and ambient particles verify that HINC operates reliably at the discussed settings of temperature and RH. As can be seen from Fig. 6, some deviation (all within instrument uncertainty) of the data points does occur. This is due to the fact that in the region of ice nucleation or droplet activation the AF (nucleation rate) is a very steep function of RH and a small change in water activity by, for example, $0.01(\sim \mathrm{RH}$ of $1 \%$ at equilibrium) can change the nucleation rate by a factor of 10 or 15 .

\subsection{Uncertainties and limit of detection (LOD)}

Uncertainties in temperature and RH to which the aerosol particles are exposed to can arise from the set wall temperatures of HINC that are measured by two thermocouples on each wall in the activation/growth section of the chamber. The thermocouples have an uncertainty of $\pm 0.1 \mathrm{~K}$. This translates into an uncertainty in $\mathrm{RH}$ at the center location of $\mathrm{RH}_{\mathrm{w}} \pm 1 \%\left(\mathrm{RH}_{\mathrm{i}}= \pm 1 \%\right)$ at a center temperature of $242 \mathrm{~K}$ and at $\mathrm{RH}_{\mathrm{W}}=104 \%$. In addition to this, the aerosol layer is only $1 / 13$ th of the total flow (for a typical sheath-to-aerosol ratio of $12: 1$ ) and, since a linear temperature gradient establishes between the warm and the cold wall, there is a temperature variation of $\pm 0.4 \mathrm{~K}$ across the aerosol layer for the temperature conditions $(242 \mathrm{~K})$ used in the field measurements presented here. The variation in temperature causes a variation in $\mathrm{RH}_{\mathrm{w}}$ of $\pm 1 \%\left(\mathrm{RH}_{\mathrm{i}} \pm 2 \%\right)$. This translates into a calculated total uncertainty of $\mathrm{RH}_{\mathrm{w}} \pm 2 \%\left(\mathrm{RH}_{\mathrm{i}} \pm 3 \%\right)$ at
$242 \mathrm{~K}$ and $\mathrm{RH}_{\mathrm{w}}=104 \%$. The validation experiments of homogeneous freezing and cloud droplet activation reveal an uncertainty of $\mathrm{RH}_{\mathrm{w}} \pm 1.5 \%$, which is slightly lower than the calculated uncertainty and shows that HINC is able to precisely establish prescribed supersaturations. Thus we take the uncertainties to be $\pm 0.4 \mathrm{~K}$ and $\mathrm{RH}_{\mathrm{w}} \pm 1.5 \%\left(\mathrm{RH}_{\mathrm{i}} \pm 3 \%\right)$, respectively.

The OPC, which is used to classify and count detected hydrometeors downstream of HINC, has a relative counting accuracy of $\pm 10 \%$ and a relative uncertainty in the sizing channels of $\pm 10 \%$. The CPC, which was used to measure the total particle concentration in parallel to the INP measurements, has a relative counting accuracy of $\pm 10 \%$, resulting in a relative uncertainty in the $\mathrm{AF}$ of $14 \%$. The DMA, which was used to size select the $\left(\mathrm{NH}_{4}\right)_{2} \mathrm{SO}_{4}$ and $\mathrm{H}_{2} \mathrm{SO}_{4}$ particles, has a relative sizing uncertainty of $3-3.5 \%$.

During an ice nucleation experiment, erroneous counts in the OPC ice channel can arise from electrical noise in the OPC or from internal ice sources such as frost falling off the warmer chamber wall giving rise to particle counts that are falsely classified as ice. In order to assess and to correct for the contribution of such false counts, filter measurements are conducted regularly before and after each sampling period to determine a background count in the following way: the instrument is set to its target temperature and $\mathrm{RH}$, and the aerosol flow is sampled through a particle filter placed upstream of the aerosol injector for $10 \mathrm{~min}$ before and after each aerosol-sampling period of $20 \mathrm{~min}$. It is observed that the background counts do not change significantly over this time and follow a Poisson distribution. The mean back- 
ground $(\mu)$ and the standard deviation $(\sigma)$ are derived from the two 10 min filter periods. The mean ambient INP counts (INP) are calculated from the counts $(\omega)$ during a $20 \mathrm{~min}$ sampling by taking the background into consideration, resulting in $\overline{\mathrm{INP}}=\omega-\mu$. The values of $\mu$ and $\sigma$ are used to assess whether the signal, i.e., $\overline{\mathrm{INP}}$, is significantly different from the noise. Therefore, the instrument's LOD for ambient INP following Poisson statistics is calculated as LOD $=\sigma$.

Comparing $\overline{\mathrm{INP}}$ to the LOD can result in one of three scenarios:

$$
\begin{aligned}
& \text { 1. } \overline{\mathrm{INP}}>\sigma, \\
& \text { 2. } \overline{\mathrm{INP}}<0, \\
& \text { 3. } 0<\overline{\mathrm{INP}}<\sigma .
\end{aligned}
$$

Scenario 1 is considered as a quantifiable INP measurement with significance because $\omega>\mu+\sigma$ and therefore above the LOD. In scenario 2, INP counts are considered to be non-quantifiable for the volume of air sampled during the 20 min period. In scenario 3 , INP counts are below the LOD but above $\mu$, therefore quantifiable but not with significant confidence. INP concentrations below the instrument LOD (scenarios 2 and 3) are included in calculations of field campaign averages. We believe that this is crucial since ambient INP concentrations are typically quite low in the FT, and scenarios 2 and 3 occurring frequently actually speaks to this low observed INP concentration. Complete ignorance of values from scenarios 2 and 3 would lead to an artificially positive bias in reporting INP concentrations (for detailed discussion see Boose et al., 2016a). The concentrations below the LOD are taken into account as their measured value (scenario 3). In the case of scenario 2, instead of using a value of zero for calculating campaign averages, a minimum quantifiable concentration for a $20 \mathrm{~min}$ period is used. This is determined by taking the minimum count possible in the OPC ice channel (1 count) and normalizing to the volume of ambient air during a $20 \mathrm{~min}$ sampling period. By doing so we acknowledge that the true concentration could be below this minimum value (shown in Table 2). In addition, by accounting for the minimum quantifiable concentration in the manner described above, we take into consideration the increase in sampled volume of ambient aerosol flow due to the use of an aerosol concentrator, applied in winters 2013 and 2014 (Boose et al., 2016a), which lowers the LOD by a certain concentration factor. For transparency we show average INP concentrations including and excluding the values below the LOD. Finally, ambient INP counts and LODs are converted to concentrations in $\operatorname{std} \mathrm{L}^{-1}$.

\section{Field measurements}

To further validate the chamber performance for field measurements, INP measurements were conducted at the JFJ during the winters of 2015 and 2016 with HINC and are com- pared to earlier measurements conducted at the same location and sampling conditions with PINC (Boose et al., 2016a) during winters 2012, 2013 and 2014. The ice nucleation measurements were performed in the deposition nucleation mode and, since winter 2014, also in the condensation freezing mode. Detailed measurement dates and sampling periods for the campaigns are given in Table 1.

HINC was set up in the field as shown in the schematic in Fig. 7. Particles were sampled from a total aerosol inlet, which is described in detail by Weingartner et al. (1999). Ambient interstitial and cloud-phase particles with diameters $<40 \mu \mathrm{m}$ at wind velocities $<20 \mathrm{~m} \mathrm{~s}^{-1}$ were sampled through an inlet heated to $293 \mathrm{~K}$ to evaporate cloud droplets and ice crystals. To exclude an additional humidity source from ambient air, the aerosol flow was passed through a diffusion dryer $\left(\mathrm{RH}_{\mathrm{w}}<2 \%\right)$ and was then split into HINC (0.22 std $\mathrm{L} \mathrm{min}^{-1}$ aerosol flow, $2.83 \mathrm{std} \mathrm{L} \mathrm{min}^{-1}$ total flow) and a CPC (TSI 3772, $1 \mathrm{std} \mathrm{L} \mathrm{min}^{-1}$ ), counting the total particle concentration in parallel.

The measurement conditions were set such that the aerosol flow experienced a constant temperature of $242 \mathrm{~K}$ and $\mathrm{RH}_{\mathrm{w}}=94 \pm 1 \%\left(\mathrm{RH}_{\mathrm{i}}=127 \pm 2 \%\right)$, relevant for heterogeneous nucleation of ice clouds, and at $T=242 \mathrm{~K}$ and $\mathrm{RH}_{\mathrm{w}}=$ $104 \pm 1.5 \%\left(\mathrm{RH}_{\mathrm{i}}=140 \pm 3 \%\right)$ in winters 2015 and 2016, relevant for the mixed-phase cloud regime. The injector position was set to an optimal residence time $(8 \mathrm{~s})$ for the aerosol particles, which takes into account prevention of ice crystal losses due to gravitational settling in the chamber but also allows for enough growth time to reach an optical diameter of $\geq 5 \mu \mathrm{m}$. Experiments with two OPCs, one in parallel and one downstream of the ice chamber, were performed in order to obtain the difference in concentrations due to aerosol particle losses. For this test, HINC was set to its field campaign at $T=242 \mathrm{~K}$ and well below water saturation to prevent any activation of particles as droplets or ice crystals. The experiments revealed a particle loss of $26 \%$ for $1 \mu \mathrm{m}$ particles, $44 \%$ for $2 \mu \mathrm{m}$ particles and $100 \%$ for particles $>5 \mu \mathrm{m}$; therefore the OPC channel used to detect ice should not be contaminated with large $(>5 \mu \mathrm{m})$ unactivated ambient particles. As such the INP measurements reported here are representative for ambient particles below $2 \mu \mathrm{m}$. This size range is characteristic for ambient aerosols at the JFJ, since particle concentrations $>1 \mu \mathrm{m}$ are naturally very low (e.g., Nyeki et al., 1998; Baltensperger et al., 1998). In addition, calculations with the Particle Loss Calculator (von der Weiden et al., 2009) revealed that $0.8 \%$ of $1 \mu \mathrm{m}$ particles, $2.6 \%$ of $2 \mu \mathrm{m}$ particles and $14-50 \%$ of $5-10 \mu \mathrm{m}$ particles should be lost in the inlet and tubing upstream of HINC, which we consider to be negligible in light of the low abundance of particles $>5 \mu \mathrm{m}$ (on the order of $0.05 \mathrm{stdL}^{-1}$ ).

For the field measurements, after the icing procedure (see Sect. 2.1) the chamber walls were set to their target temperature, such that a center aerosol temperature of $242 \mathrm{~K}$ and a $\mathrm{RH}_{\mathrm{W}}$ of $94 \%$ were achieved. While the chamber cooled down to these conditions, it was flooded with filtered dry air 
Table 1. Field measurement period and respective total sampling time of INP measurements and cloud water samples. Measurements were performed with PINC (winter 2012-2014) and HINC (winter 2015 and 2016).

\begin{tabular}{llllrrr|r}
\hline Measurements & Start & End & Breaks & \multicolumn{3}{c|}{ Total sampling time (h) } \\
\cline { 4 - 7 } & & & & \multicolumn{3}{c}{ PINC/HINC } & Cloud water \\
\cline { 4 - 7 } & & & & $T(\mathrm{~K})$ & $\mathrm{RH}_{\mathrm{w}}$ 93/94\% & $\mathrm{RH}_{\mathrm{w}}-104 \%$ & \\
\hline Winter 2012* & 12 Jan & 27 Jan & - & 241 & 62.3 & - & \\
Winter 2013* & 21 Jan & 28 Feb & - & 241 & 138.9 & - & \\
Winter 2014* & 23 Jan & 16 Feb & - & 241 & 54.6 & 28.5 & 67.8 \\
Winter 2015 & 24 Jan & 9 Feb & - & 242 & 16 & 26 & 146 \\
Winter 2016 & 13 Jan & 6 Mar & 1 Feb-26 Feb & 242 & 17.1 & 99 & 42.5 \\
\hline
\end{tabular}

* Boose et al. (2016a) measured with PINC

to prevent moist room air from contaminating the iced chamber walls. When the target temperature and $\mathrm{RH}$ was reached, a $10 \mathrm{~min}$ filter measurement, to quantify the background counts, was conducted, followed by a $20 \mathrm{~min}$ aerosol measurement and another $10 \mathrm{~min}$ filter measurement. Following this procedure, the RH was further increased to $104 \%$, and the background-sample-background measurement cycle was repeated.

To avoid depletion of the ice layers in HINC, sampling time was limited to a maximum of $14 \mathrm{~h}$, of which approximately $50 \%$ was performed during nighttime, namely from 19:00 to 07:00.

\subsection{Location}

Measurements were performed at the JFJ, located in the Bernese Alps ( $3580 \mathrm{~m}$ a.s.l.; 46 $33^{\prime} \mathrm{N}, 7^{\circ} 59^{\prime} \mathrm{E}$ ). The research facility is a Global Atmospheric Watch (GAW) monitoring station and part of the ACTRIS2 Infrastructure (European Research Infrastructure for the observation of Aerosol, Clouds, and Trace gases), the Swiss National Air Pollution Monitoring Network (NABEL) and the SwissMetNet meteorological network. The station is located on an exposed mountain col, only surrounded by firn ice and rocks, without noticeable influence from local vegetation. Due to its elevation, the site is mostly located in the FT and represents background aerosol concentrations (Baltensperger et al., 1997). It can be influenced by local emissions due to daytime tourist activities and boundary layer injections in the warmer season (Lugauer et al., 1998; Zellweger et al., 2003; Collaud Coen et al., 2011; Griffiths et al., 2013; Herrmann et al., 2015). In addition, the station is regularly affected by Saharan dust events (SDEs) where Saharan dust is transported within the FT to the JFJ (Collaud Coen et al., 2004). Continuous measurements of aerosol physical properties (e.g., Baltensperger et al., 1997; Bukowiecki et al., 2016), trace gases (Steinbacher et al., 2016) and meteorological conditions (Appenzeller et al., 2008) are conducted and give additional information on aerosol properties and air mass origin to complement the INP measurements conducted.

\subsection{Aerosol particle measurements}

A custom-built scanning mobility particle sizer (SMPS), consisting of a DMA (TSI 3071) and a CPC (TSI, 3775), measured the aerosol size distributions between 20 and $600 \mathrm{~nm}$ in diameter with a time resolution of 6 min (Herrmann et al., 2015). Larger-sized particles were measured by an OPC (GRIMM Dust Monitor 1.108; size range 0.23-16.4 $\mu \mathrm{m}$ ). To merge the respective size distributions, the mobility and optical diameters were converted to volume equivalent diameters, assuming a particle density of $1565 \mathrm{~kg} \mathrm{~m}^{-3}$ (Sjogren et al., 2008) and a unity shape factor. An integrating nephelometer (TSI, 3563) and an aethalometer (MAGEE scientific, AE31) measured the total aerosol scattering coefficients (three wavelengths) and the absorption coefficients (seven wavelengths), respectively. From this the single scattering albedo (SSA) at 450, 550 and $700 \mathrm{~nm}$ is derived, as well as the SSA Angström exponent, as described by Collaud Coen et al. (2004). For the normal background aerosol, the SSA increases with wavelength, resulting in a positive SSA Ångström exponent, while for Saharan dust particles, due to their larger size and different optical properties, the SSA decreases with wavelength and its exponent becomes negative. A SDE is declared if the SSA exponent is negative for more than 4 consecutive hours. The aethalometer also measures the equivalent black carbon (eBC) mass concentration, derived from the attenuation measurement by applying the factory standard mass attenuation cross section of $16.6 \mathrm{~m}^{2} \mathrm{~g}^{-1}$ at $880 \mathrm{~nm}$.

\subsection{Cloud water samples}

Cloud water samples at the JFJ were collected to determine the air mass origin and aerosol source regions by analyzing the samples for trace chemical elements (e.g., Zipori et al., 2015) and as such were taken in parallel to the ice nucleation measurements during cloudy periods (see Table 1 for sampling times). Samples were collected on the terrace next to the laboratories at the JFJ, with a home-built plexiglass plate $(20 \times 20 \times 0.5 \mathrm{~cm})$ which was attached vertically to the 

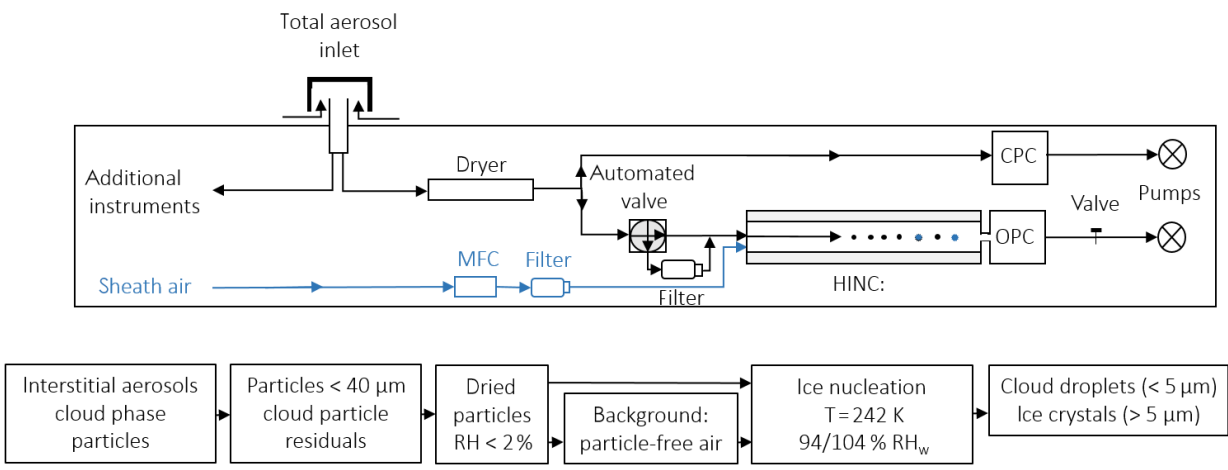

Figure 7. Schematic of aerosol flow and instrument setup during field measurements at the JFJ research station.

railing, facing the windward side. Prior to the sampling, the plate was cleaned with a super pure $(65 \%)$ nitric acid solution $(0.1 \% w / w)$ and double-deionized water, and a blank sample with double-deionized water was taken by pouring it over the sampler. The sampling method works only for supercooled cloud droplets which freeze upon contact with the plate and not for ice crystals and precipitation particles, since ice crystals are deflected, and snowflakes are too heavy to stick to the sampler. The supercooled cloud droplets remain as an ice layer on the sampler, which is melted into prerinsed plastic bags and stored in Falcon ${ }^{\circledR}$ tubes. The samples were sent to the clean room laboratory at the Hebrew University of Jerusalem, where they were analyzed for 23 trace metals using inductively coupled plasma mass spectrometer (ICP-MS, Agilent, 7500cx). Detailed information regarding sample handling, analysis protocol and quality control can be found in Zipori et al. (2012, 2015).

The interpretation of the analysis of elemental concentrations was focused on sodium $(\mathrm{Na})$, aluminium $(\mathrm{Al})$, lead $(\mathrm{Pb})$ and strontium $(\mathrm{Sr})$. Sodium chloride $(\mathrm{NaCl})$ is a natural component of the ocean, and the positive ion $\mathrm{Na}^{+}$is found in an appreciable quantity in sea spray aerosol. In addition, $\mathrm{Na}^{+}$ found in cloud samples is always accompanied by $\mathrm{Sr}$. The fraction of $\mathrm{Sr}$ coming from sea salt $\left(f(\mathrm{Sr})_{\mathrm{ss}}\right)$ is used as an indication for air masses influence and is calculated using the following equation:

$f(\mathrm{Sr})_{\mathrm{ss}}=\left[\frac{\mathrm{Sr}}{\mathrm{Na}}\right]_{\mathrm{ss}} \times\left[\frac{\mathrm{Na}}{\mathrm{Sr}}\right]_{\mathrm{samp}}$,

where $f(\mathrm{Sr})_{\mathrm{ss}}$ is the fraction of $\mathrm{Sr}$ contributed from sea salt, $[\mathrm{Sr} / \mathrm{Na}]_{\mathrm{ss}}$ is the Sr-to-Na ratio found in sea salt and $[\mathrm{Sr} / \mathrm{Na}]_{\text {samp }}$ are the concentrations of $\mathrm{Na}$ and $\mathrm{Sr}$ found in the samples (Herut et al., 1993). Furthermore, elemental ratios such $\mathrm{Na} / \mathrm{Al}, \mathrm{Pb} / \mathrm{Al}$ and $\mathrm{Pb} / \mathrm{Na}$ were used as indications for marine/dust, anthropogenic/dust and anthropogenic/marine influence in the samples, respectively.

In addition to the chemical analysis, $\mathrm{Sr}$ isotopic ratios were also measured with a multi-collector inductively coupled plasma mass spectrometer (MC-ICP-MS, NEPTUNE
Plus). Sr separation was done with $\mathrm{Sr}-\mathrm{Spec}$ resin flowing, a method described by Stein et al. (1997). Since marine ${ }^{87} \mathrm{Sr} /{ }^{86} \mathrm{Sr}$ is constant with a value of 0.70917 (Hodell et al., 1990) while basalt and volcanic rocks have a lower ratio and Saharan dust has higher ratio (Capo et al., 1998, and references therein), this parameter can be used to determine the prevailing aerosol type in the sample due to scavenging.

\subsection{Back trajectories and source sensitivities}

To obtain information on the trajectories of the air masses arriving at the JFJ, an ensemble of 10-day back trajectories was calculated every $6 \mathrm{~h}$ with the LAGRANTO model (Wernli and Davies, 1997), based on ECMWF Integrated Forecast System wind fields. Back trajectories at five different locations, one ending at the JFJ and four displaced by $0.5^{\circ}$ to the north and south, are started at four different altitude levels of $654,704,604$ and $754 \mathrm{hPa}$. In addition, source sensitivities, which determine the potential contribution of groundbased regions to be the source region of the particles arriving at the JFJ, are derived from the Lagrangian particle dispersion model, FLEXPART, products browser at EMPA (http://lagrange.empa.ch/FLEXPART_browser/; Stohl et al., 2005; Sturm et al., 2013; Pandey Deolal et al., 2014). The source sensitivities thus give the possible origin of the particles as a probability of the geographical regions from which the aerosol particles were emitted. It simulates the release of 50000 particles every $3 \mathrm{~h}$ at the JFJ and traces the particles backwards driven by ECMWF Integrated Forecast System wind fields.

\subsection{Assessment of free-tropospheric conditions}

Different proxies are used in this study to qualitatively assess the exposure of the site to the FT. The ratio of total reactive nitrogen $\left(\mathrm{NO}_{y}\right.$, as the sum of nitrogen oxide, nitrogen dioxide and its atmospheric oxidation products) to carbon dioxide (CO) is commonly used as an indicator for boundary layer injections into the FT at elevated stations (Zellweger et al., 2003; Zanis et al., 2007; Pandey Deolal et al., 2013; 
Griffiths et al., 2014; Herrmann et al., 2015; Boose et al., 2016a). Both tracers are subject to emissions from anthropogenic sources, however, the $\mathrm{NO}_{y} / \mathrm{CO}$ ratio decreases with increasing transport (aging) of the air mass as $\mathrm{CO}$ is inert within the timescale of interest (days) while the concentration decay rate of $\mathrm{NO}_{y}$ is higher. Thus, a $\mathrm{NO}_{y} / \mathrm{CO}$ ratio of $0.0057 \mathrm{ppbppb}^{-1}$ was chosen to distinguish between FT conditions and boundary layer influence, in accordance with the value reported for wintertime measurements at the JFJ by Zellweger et al. (2003). $\mathrm{NO}_{y} / \mathrm{CO}$ ratios below 0.0057 indicate FT conditions while an influence of boundary layer is likely for ratios above this value.

The concentration of particles $>90 \mathrm{~nm}$ was also used to identify FT conditions, since particles of this size are not formed in the FT but are transported from the boundary layer, and therefore gives information on boundary layer influence (Herrmann et al., 2015). A threshold of $100 \mathrm{~cm}^{-3}$ was chosen, below which the air mass is assumed to be free tropospheric. It should be mentioned that the concentration of particles $>90 \mathrm{~nm}$ can be influenced by the occurrence of largersized dust particles and should therefore be considered with care during SDEs which are transported in the FT.

\section{Results}

This is the first study where a chamber of HINC's design has been characterized and used for field measurements at conditions relevant to the mixed-phase cloud regime ( $T>235 \mathrm{~K}$ and $\mathrm{RH}_{\mathrm{w}}>100 \%$ ). An identical chamber (Kanji and Abbatt, 2009) has been used for online field studies (Ladino et al., 2016) and processing of resuspended field samples (Wilson et al., 2015) at $233 \mathrm{~K}$ and water-subsaturated conditions. Here we compare results from two field campaigns in winter 2015 and 2016 to previously conducted INP measurements in the same season with PINC (Boose et al., 2016a). These results extend the time series of INP measurements below water saturation since winter 2012 and above water saturation since winter 2014 at the JFJ, which also contributes to the monitoring of INPs during winter months.

In winters 2015 and 2016, air masses containing high INP concentrations were sampled, which were excluded from the comparison of the background campaign average INP concentrations. Furthermore, two such air masses from winter 2015 are discussed to relate the observed increase in INP concentrations to aerosol properties and air mass origin and therefore examine the possible sources of ambient INPs. In winter 2015, the JFJ experienced FT conditions during 79\% of the sampling time, with no specific increase in INP concentrations during boundary layer influence, while in winter 2016 the site was in the FT $92 \%$ of the time and an event of increased INP concentration was observed during boundary layer influence, which is also excluded from the comparison of campaign averages in this study.

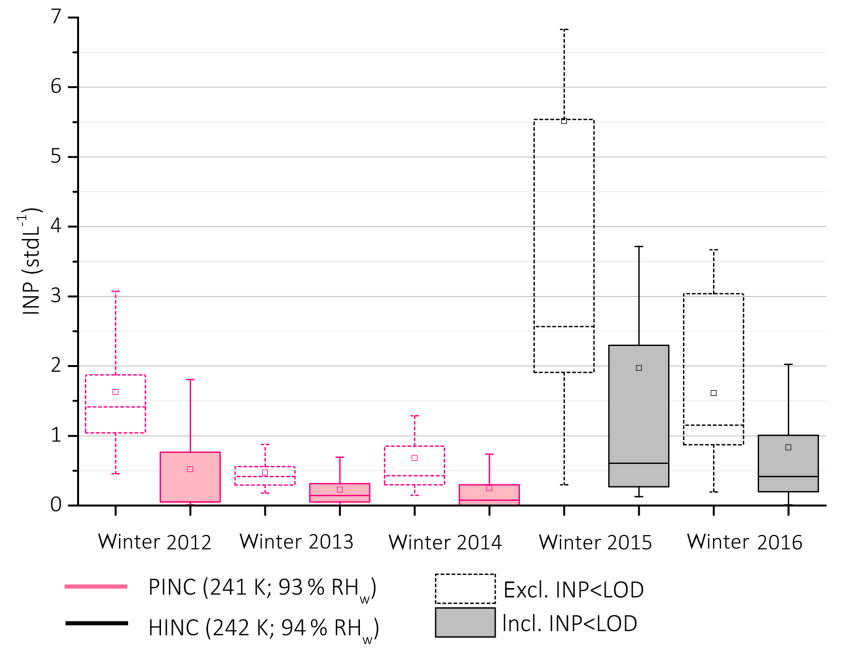

Figure 8. Averaged INP concentrations observed below water saturation (see legend for exact temperature and RH conditions). Dashed box plots represent only INPs > LOD; solid box plots include INPs < LOD (see Sect. 2.3 for details). Median: middle bar; mean: open square data point; box: interquartile range (25th to 75th percentiles); whiskers: 5th and 95th percentiles. Data used to produce the distributions exclude contributions from measurements during periods of SDEs and air masses of marine influence at the JFJ (see Sect. 4.2) with anomalously high INP concentrations. See Table 1 for field campaign sampling times.

\subsection{Field measurements of INPs: winters 2015 and 2016}

\subsubsection{INP concentrations at water-subsaturated conditions (deposition nucleation)}

Measurements below water saturation performed with HINC during winters 2015 and 2016 are shown in Fig. 8 and are compared to the measurements performed with PINC in winters 2012-2014 taken from Boose et al. (2016a). Campaign median and mean INP concentrations are given in Table 2 . The solid boxes in Fig. 8 include the entire distribution of INP concentrations measured including those below the LOD, whereas the dashed ones include only the INP concentrations above the LOD (see Sect. 2.3). Excluding INP below the LOD artificially positively biases the data to higher INP values; therefore, in discussing the results below, the averages that include INP concentrations below the LOD are considered. During winters 2013 and 2014 an aerosol concentrator was used, which increased the signal-to-noise ratio by a factor of 3, and therefore the LOD for ambient INP was lowered.

The median (mean) INP concentration below water saturation, for all five field campaigns, is $0.1(0.6) \mathrm{stdL}^{-1}$. The PINC measurements in winter 2012-2014 give a median (mean) INP concentration of $0.1(0.2) \mathrm{std} \mathrm{L}^{-1}$, as compared to a HINC median (mean) concentration of $\leq 0.2$ 
Table 2. Campaign INP concentrations ( $\operatorname{std~L}^{-1}$ ) excluding known cases of high INP concentrations, as measured with PINC (winter 20122014) and HINC (winter 2015 and 2016). Values are given for each field campaign (rows 1 and 2) and as averages over the PINC and HINC campaigns (rows 3 and 4). Measurements above water saturation were not conducted prior to 2014. INP concentrations here consider data below the LOD and can therefore differ from values reported in Boose et al. (2016a).

\begin{tabular}{ll|r|r|r|r|r}
\hline $\mathrm{RH}_{\mathrm{W}}$ & $\mathrm{INP}\left(\mathrm{stdL}^{-1}\right)$ & Winter 2012 & Winter 2013 & Winter 2014 & Winter 2015 & Winter 2016 \\
\hline $93 / 94 \%$ & median & $<0.05^{*}$ & 0.1 & 0.1 & $\leq 0.2^{*}$ & $\leq 0.2^{*}$ \\
& mean & 0.2 & 0.2 & 0.3 & 1.7 & 0.7 \\
\hline $104 \%$ & median & - & 2.2 & 2.8 & 4.7 \\
& mean & - & 4.2 & 5.0 & 8.2 \\
\hline $93 / 94 \%$ & median & \multicolumn{2}{|c|}{0.1} & & $\leq 0.2^{*}$ \\
& mean & & 0.2 & & 1.2 \\
\hline $104 \%$ & median & - & 2.2 & 3.8 \\
& mean & - & 4.2 & 6.6 \\
\hline
\end{tabular}

* Averaged INP concentrations reported as the minimum quantifiable INP concentration, for data points that fall under scenario 2 (see Sect. 2.3), which are included in the averaging as this minimum.

(1.2) $\operatorname{std}^{-1}$ for winters 2015 and 2016 (Table 2, third row, last column). The natural variation in reported INP concentrations at a given temperature and RH condition can be as much as an order of magnitude after accounting for contributions from known INP sources. INP concentrations were comparable in different years, given that the minimum and maximum INP concentrations below water saturation overlap.

\subsubsection{INP concentrations at water-saturated conditions (condensation freezing)}

Figure 9 presents INP measurements above water saturation for winter 2014 (Boose et al., 2016a) and for winters 2015 and 2016 from this study. INP concentrations above water saturation are typically higher by approximately a factor of 10 as compared to water-subsaturated conditions (Fig. 8), yielding a much higher signal-to-noise ratio with only a few data points falling below the LOD. As such the differences between the solid and dashed box plots in Fig. 9 are small.

The median (mean) INP concentration in winter 2014 as measured with PINC was 2.2 (4.2) std $\mathrm{L}^{-1}$ and in winters 2015 and 2016, as measured with HINC, was 2.8 (5.0) and 4.7 (8.2) std $\mathrm{L}^{-1}$, respectively (Table 2 , second and fourth rows). In winter 2016, the INP concentrations are higher compared to the previous two winters. We explain this by the higher frequency of dust aerosol during that particular season. During the time of the measurements, two SDEs were detected based on the SSA Ångström exponent criteria, but it is possible that the station was under the influence of dust particles without identification of a dust event, which requires the condition of 4 continuous hours of a negative exponent of the SSA. This would imply that the majority of ambient particles were non-dust particles but dust could still contribute to the total aerosol loading. This is supported by source emission sensitivities derived by FLEXPART, in-

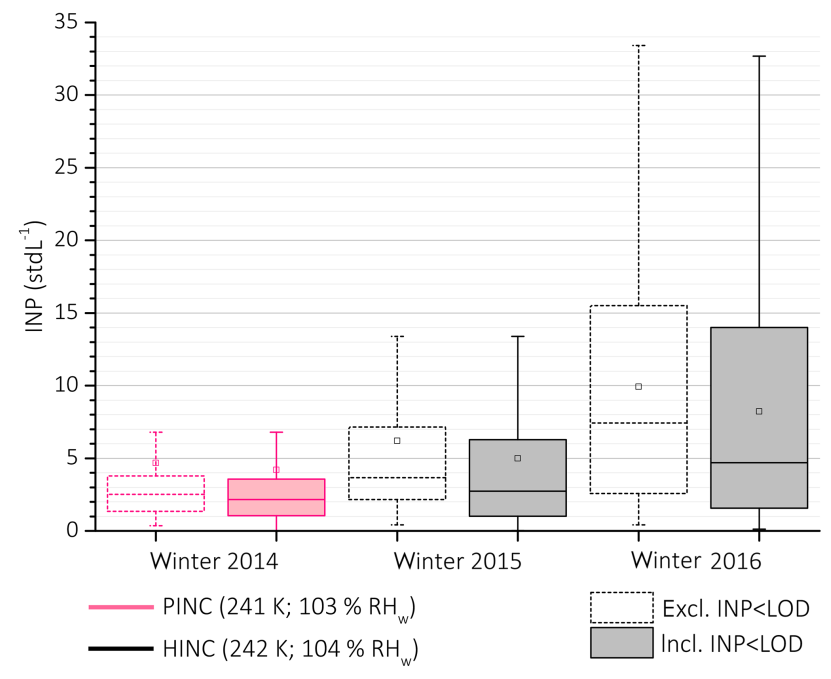

Figure 9. Averaged INP concentrations observed above water saturation (see legend for exact temperature and $\mathrm{RH}$ conditions). Dashed box plots represent only INPs > LOD, while solid box plots include INPs $<$ LOD (see Sect. 2.3 for details). Median: middle bar; mean: open square data point; box: interquartile range (25th to 75th percentiles); whiskers: 5th and 95th percentiles. Data used to produce the distributions exclude contributions from measurements during periods of known air masses arrived at the JFJ (see Sect. 4.2) with anomalously high INP concentrations. See Table 1 for field campaign sampling times.

dicating the Sahara as a source region for several days in addition to the declared SDEs, and by the concurrent increase in the particle concentrations $>0.4 \mu \mathrm{m}$, which is typical for dust. Therefore, this difference in INP concentrations between 2015 and 2016 can be explained by a natural interannual variation. However, the difference in median and mean INP concentration is only a factor of 2 . As compared 


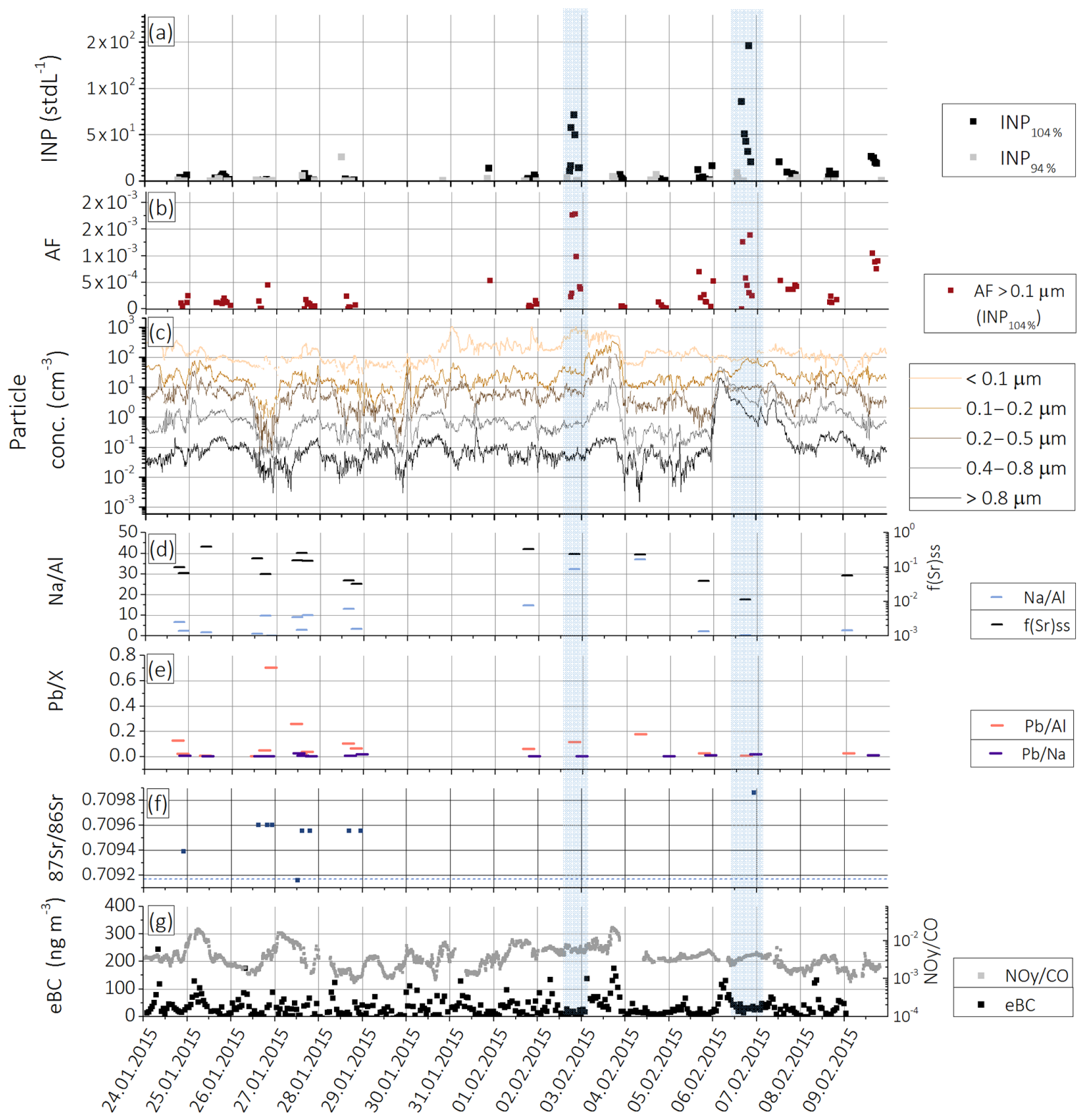

Figure 10. Time series of (a) INP concentrations at $242 \mathrm{~K}$ and $\mathrm{RH}_{\mathrm{W}}=104$ and $94 \%$ measured with HINC; (b) $\mathrm{AF}_{\text {of INP }} 104 \%$ considering particles $>0.1 \mu \mathrm{m}$; (c) particle concentrations $<0.1,0.1-0.2,0.2-0.5 \mu \mathrm{m}$ (SMPS) and 0.4-0.8 and $>0.8 \mu \mathrm{m}$ (OPC), given in volume equivalent diameter; cloud water sample analysis, given in ratios of mass of (d) $\mathrm{Na} / \mathrm{Al}$ and $f(\mathrm{Sr})_{\mathrm{ss}}$ and $(\mathbf{e}) \mathrm{Pb} / \mathrm{Al}$ and $\mathrm{Pb} / \mathrm{Na}$; (f) isotopic ratio ${ }^{87} \mathrm{Sr} /{ }^{86} \mathrm{Sr}$, the dashed line represents the constant value for marine sea salt $(=0.70917) ;(\mathrm{g})$ eBC mass concentration and $\mathrm{NO}_{y} / \mathrm{CO}$ ratio.

to the PINC measurements in winter 2014, HINC measures higher median and mean INP concentrations by up to a factor of 2 , which is considered low given that the possible range of observed INP concentrations for a given temperature can be much higher, as observed by, e.g., Schrod et al. (2017) and DeMott et al. (2010).

\subsection{Case studies}

INP measurements were performed with HINC from 24 January to 9 February 2015 at the JFJ (Fig. 10). In this sec- tion, results from two events during winter 2015 are presented, for which INP concentrations above water saturation increased significantly above the campaign average. The events, which lasted several hours with higher INP concentrations, are shown in Fig. 10a. We discuss the air mass characteristics and aerosol properties that identify the most likely sources of the observed increase in ice-active particles. 

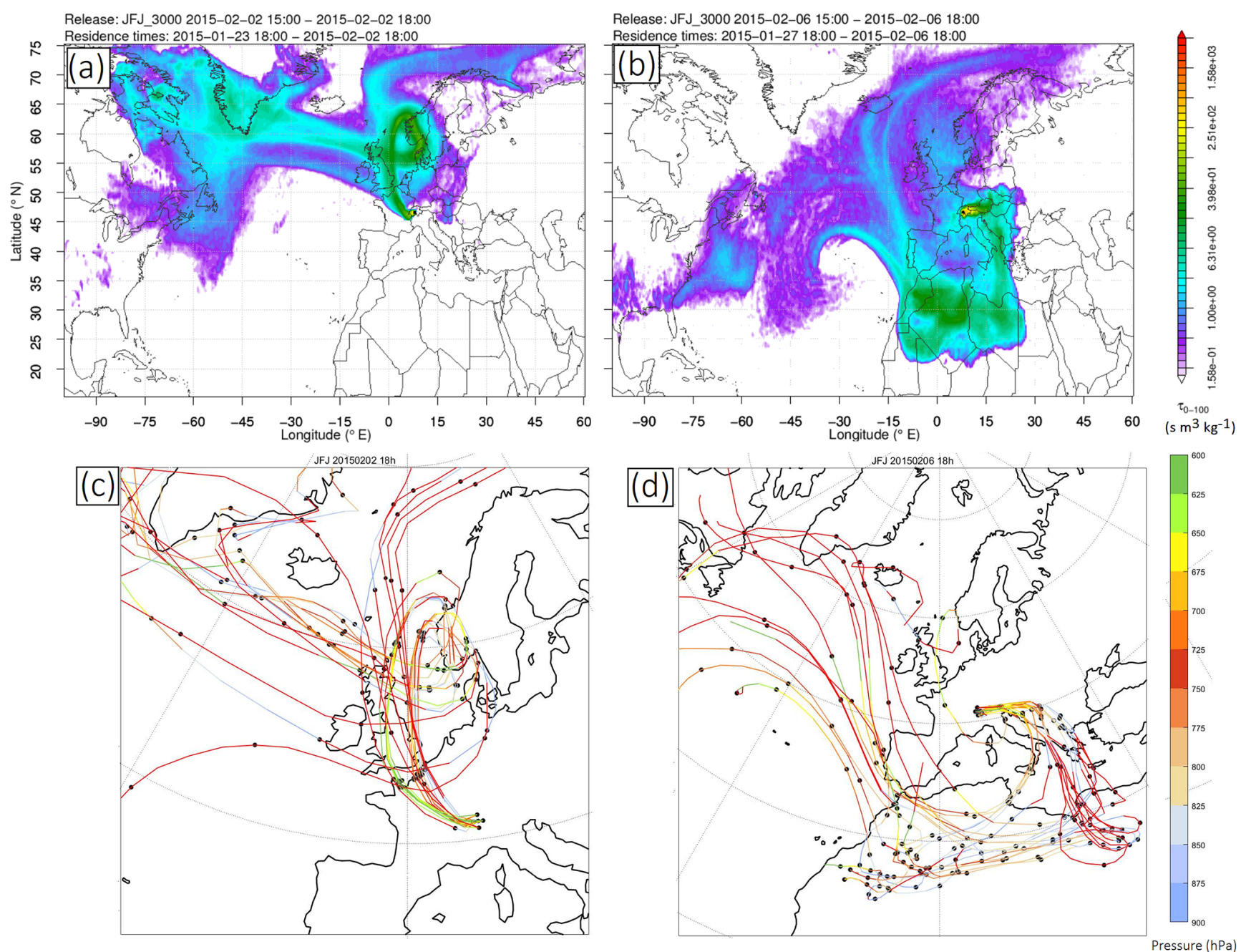

Figure 11. (a and b) FLEXPART emission sensitivity fields for 2 (a) and 6 (b) February 2015, calculated $100 \mathrm{~m}$ above model ground level (http://lagrange.empa.ch/FLEXPART_browser/; Stohl et al., 2005; Sturm et al., 2013; Pandey Deolal et al., 2014); the color code represents the strength of source region contributions to the aerosol burden given in a unit flux per area. (c and d) Ten-day back trajectories for 2 (c) and 6 (c) February 2015 calculated with LAGRANTO (Wernli and Davies, 1997); the color code represents the trajectory pressure above model ground, and the black points indicate each $24 \mathrm{~h}$ back calculation.

\subsubsection{Case 2 February 2015: marine air}

On 2 February INP concentrations increased up to $72.1 \mathrm{stdL}^{-1}$ with median (mean) concentrations of 16.3 (33.3) $\operatorname{std~L}^{-1}$ over a time of $5 \mathrm{~h}$ (Fig. 10a). Also an increase in the AF (considering particles $>0.1 \mu \mathrm{m}$ ) by an order of magnitude was observed from the campaign median (mean) value of $1.3 \times 10^{-4}\left(2.8 \times 10^{-4}\right)$ to a maximum of $1.8 \times 10^{-3}$ indicating that the increase was due not only to a new increase in particle number but also to a higher fraction of the aerosol being ice active (Fig. 10b).

The SSA showed a wavelength-dependent increase, which is typical for background aerosol conditions at the JFJ, and is an indication for the absence of Saharan dust. The particle concentration in the size bin $0.4-0.8$ and $>0.8 \mu \mathrm{m}$ did not increase (Fig. 10c), confirming no influence from larger (dust) particles. The ratio $\mathrm{Na} / \mathrm{Al}$ derived from the cloud water samples during this sampling period increased (Fig. 10d) and, at the same time, $f(\mathrm{Sr})_{\mathrm{ss}}$ increased (Fig. 10d), which suggests that the air mass arriving at the JFJ was of marine origin. Sr isotopic ratios, which could strengthen the identification of a marine source, were not available for that day due to the small volume of cloud water collected which was not sufficient for the isotopic analyses. However, source sensitivities (Fig. 11a) indicate most sources over the North Sea as well as source regions over the Northern Atlantic and Norwegian Sea. In addition to the source sensitivities, 10-day back trajectories also support marine sources and also reveal that the air parcel traveled over northern Europe, England and France to the JFJ (Fig. 11c) and could have been sub- 


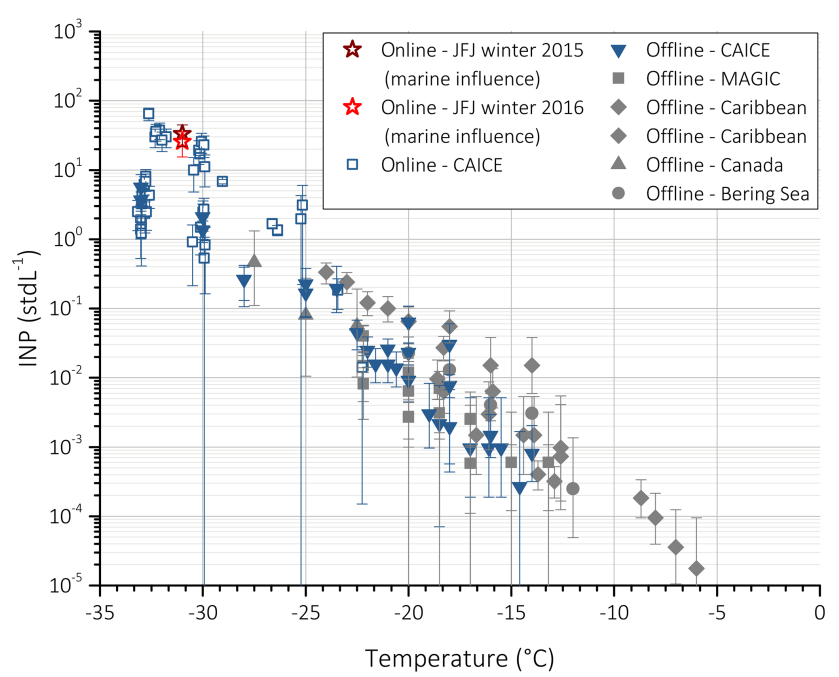

Figure 12. INP concentrations as a function of sampling temperature. Data represent measurements of sea spray particles (DeMott et al., 2016) in the laboratory (blue) at the Center for Aerosol Impacts on Climate and the Environment (CAICE) and for ambient marine boundary layer particles (grey), during different campaigns (see label for respective field campaign name), and two marine events obtained at the JFJ (stars, this study). Measurements are differentiated between online (open symbols) and offline (filled symbols) freezing methods. Laboratory data are normalized to total particle concentrations of $150 \mathrm{~cm}^{-3}$. Error bars are given for twice the Poisson sampling error and give up-to-date values, which can differ from published ones in DeMott et al. (2016) (personal communication with the author Paul J. DeMott).

ject to aging and anthropogenic emissions. Indeed on that day an increase in particle concentrations $<0.1 \mu \mathrm{m}$ was observed (Fig. 10c), which could be an indication for an anthropogenic influence. This is supported by the finding of an increased $\mathrm{NO}_{y} / \mathrm{CO}$ ratio (Fig. 10g), which is a tracer for anthropogenic influence of the air mass arriving at the JFJ. Because eBC mass concentrations were low during that time (Fig. 10g), a higher contribution of marine particles than of the anthropogenic emissions to the observed INPs is likely. However, the influence of aging processes resulting in internal mixing of the marine particles with anthropogenic emissions arriving at the JFJ cannot be ruled out.

The cloud sample analysis of the $\mathrm{Na} / \mathrm{Al}$ ratio and the $f(\mathrm{Sr})_{\mathrm{ss}}$, as well as the isotopic ratio of $\mathrm{Sr}$ (Fig. 10d, e and $\mathrm{f}$, respectively), revealed a marine source of particles on the morning of 27 January. Unfortunately, no INP measurements are available for that time, only later from the same day, when the marine influence decreased and INP measurements were within the campaign average. Another marine air mass event was detected in winter 2016, on 6 March (data not shown here), when the indicators discussed above for marine influence (i.e., from cloud water samples) were similar. Using the same methods discussed above, we identified the INP concentration during the winter 2016 marine event to be on the same order of magnitude as during the winter 2015 marine event, with a median (mean) INP concentration of 14.9 (25.5) $\operatorname{stdL}^{-1}$ and a maximum concentration of $176.8 \mathrm{std} \mathrm{L}^{-1}$.

In Fig. 12 we compare the INP concentrations from the periods of marine influence at the JFJ to those reported in DeMott et al. (2016) for marine aerosols from online and offline INP measurements from different laboratory and field samples of sea waters. We find good agreement at $242 \mathrm{~K}$ for the measured concentrations at the JFJ during the two marine events compared to the laboratory and field measurements of marine INPs. We also note that during the occurrence of a marine event at the JFJ an increase in the AF (Fig. 10b) is observed simultaneously, indicating an enrichment of ice-active particles compared to the background levels of INP. Furthermore, these observations might also suggest that long-range transport of small marine particles to the JFJ does not result in a suppression of their ice nucleation abilities, but rather the INPs retain their ice nucleation abilities during transport to the JFJ despite possible mixing with particles from anthropogenic emissions. Modeling studies have reported that marine aerosols as INPs are relevant on a global scale (Yun and Penner, 2013), especially in remote marine areas where dust abundance is low (Burrows et al., 2013; Wilson et al., 2015; Vergara-Temprado et al., 2017).

\subsubsection{Case 6 February 2015: SDE}

An increase in INP concentrations was measured on 6 February with values up to $146.2 \mathrm{std} \mathrm{L}^{-1}$ and with a median (mean) concentration of 42.6 (55.4) $\mathrm{std}^{-1}$ (Fig. 10a). The AF also increased by a factor of 10 , up to $1.4 \times 10^{-3}$ (Fig. 10b). During that time a SDE was detected based on the SSA Ångström exponent criterion (see Sect. 3.2). An increase in the particle concentration $0.4-0.8$ and $>0.8 \mu \mathrm{m}$ (Fig. 10c) supports the presence of larger mineral dust particles, as well as a decrease in the $\mathrm{Na} / \mathrm{Al}$ ratio (Fig. 10d), indicating a dusty air mass rich in alumina silicate minerals. Emission sensitivities (Fig. 11b) identify a large area over the central Sahara as a particle source region, and back trajectories calculated for this day (Fig. 11d) show that the air parcel was traveling from the Sahara over the Mediterranean to the Alps. An influence from the ocean on the air mass composition cannot be excluded according to the back trajectories, as the height of the calculated back trajectories over the Mediterranean Sea was $>950 \mathrm{hPa}$, which indicates some contact with boundary layer air. In addition, source sensitivities show a possible influence from this region. Chemical analysis of cloud water sampled at the JFJ during the arrival of the respective air mass reveals that the $f(\mathrm{Sr})_{\mathrm{ss}}$ is low (Fig. 10d), which confirms a low marine influence. In addition, the $\mathrm{Sr}$ isotopic ratio ${ }^{87} \mathrm{Sr} /{ }^{86} \mathrm{Sr}$ is increased to a value of 0.70986 (Fig. 10f), which is an indication for Saharan dust (Capo et al., 1998, and references therein). Furthermore, ratios of $\mathrm{Na} / \mathrm{Al}$ and $\mathrm{Pb} / \mathrm{Al}$ were low due to an enrichment of $\mathrm{Al}$ in the water 
sample. The eBC mass concentration and the $\mathrm{NO}_{y} / \mathrm{CO}$ ratio are low (Fig. 10g), which also supports a pristine air mass.

Below water saturation, four measurements of INP concentrations were taken during the dust event, two measurements below the LOD and two measurements with increased concentrations of 3 and $8.8 \mathrm{std}^{-1}$, as compared to a campaign median (mean) value of $\leq 0.2 \operatorname{stdL}^{-1}\left(1.7 \mathrm{stdL}^{-1}\right)$. For conditions below water saturation, dust events yielding higher INP concentrations at the JFJ have been reported before (Chou et al., 2011) and in the Saharan air layer by aircraft sampling (DeMott et al., 2003b). At water-saturated conditions, this is the first study to clearly show that during a SDE at the JFJ an increase in INPs is observed at $242 \mathrm{~K}$. This agrees with the findings of an increase in INP concentrations observed during minor influence of Saharan dust (Boose et al., 2016b). We note that at $265 \mathrm{~K}$ an increase in immersion INPs at the JFJ was not observed during SDEs (Conen et al., 2015), indicating that dust contributes to ice nucleation at colder temperatures as has been previously suggested in numerous studies (see references in Hoose and Möhler, 2012; Murray et al., 2012; Kanji et al., 2017).

A calculation based on the size distribution of ambient particles from the field campaigns at the JFJ reveals that the maximum contribution of $1 \%$ aerosol particles $>5 \mu \mathrm{m}$ remain unactivated in HINC would be $0.026 \operatorname{stdL}^{-1}\left(0.285 \mathrm{std}^{-1}\right)$ in winter 2015 (winter 2016), during a time when INP concentrations reached $85.5 \mathrm{std}^{-1}$ $\left(154.5 \mathrm{std} \mathrm{L}^{-1}\right)$. Thus a positive bias of larger unactivated particles to INP concentrations should be insignificant.

Also an increase in larger particles was observed on 3 February (Fig. 10c), particularly in the size range 0.1$0.8 \mu \mathrm{m}$. During this period, the SSA increased with wavelength, which is atypical for Saharan dust, and also no decrease in the $\mathrm{Na} / \mathrm{Al}$ ratio was observed. In addition, neither source sensitivities nor back trajectories (see Fig. C1 in Appendix C) showed influence from the Sahara. However, during this time construction work on the tunnel systems in the Alps under the JFJ was conducted, possibly leading to the abrasion of rocks and the emission of larger particles. These particles were not ice active at the sampling conditions in HINC, since an increase in INP concentration above or below water saturation was not observed.

\section{Conclusions}

This is the first study in which an INP counter of HINC's design has been used to quantify ambient INP concentrations at temperature and $\mathrm{RH}$ conditions relevant for mixed-phase cloud formation, where both liquid and ice particles can coexist. We demonstrated that HINC, based on the design of the UT-CFDC (Kanji and Abbatt, 2009), was successfully deployed to sample ambient INP concentrations. The RH and temperature accuracy were determined for the temperature range $223-263 \mathrm{~K}$ and at conditions of sub- and super- saturation with respect to water by observing droplet activation of sulfuric acid particles and deliquescence of sodium chloride and ammonium sulfate particles. In addition, homogenous freezing of sulfuric acid aerosols at temperatures $<235 \mathrm{~K}$ also validated accurate conditions in HINC for ice formation. The uncertainty in INP measurements in HINC arises from the variation in temperature and $\mathrm{RH}$ to which the aerosols in the chamber are exposed, which are $T \pm 0.4 \mathrm{~K}$ and $\mathrm{RH}_{\mathrm{w}} \pm 1.5 \%\left(\mathrm{RH}_{\mathrm{i}} \pm 3 \%\right)$ for $T>235 \mathrm{~K}$. These variations can lead to uncertainties in AFs in the region of activation and nucleation where nucleation rates are a steep function of RH. Conducting field measurements of INPs with ambient aerosols at $242 \mathrm{~K}$ and $\mathrm{RH} 104 \%$, where we ensure all particles are fully activated to droplets, reduces the associated uncertainties in INP concentrations arising from the RH variation in the chamber. HINC was characterized for an optimum residence time to maximize the growth time of the ice crystals but avoid particle losses due to gravitational settling in the horizontally oriented chamber. INP concentration measurements with HINC from winters 2015 and 2016 at the JFJ were presented at $242 \mathrm{~K}$ for $\mathrm{RH}_{\mathrm{w}}=94$ and $104 \%$. Median INP concentrations, excluding specific events of high INP concentrations, were on average $\leq 0.2 \mathrm{std} \mathrm{L}^{-1}$ below water saturation, and these low concentrations are within the range of the median INP concentration of $0.1 \mathrm{stdL}^{-1}$ measured at the same site before, with PINC (Boose et al., 2016a), during winters 2012-2014. Above water saturation, INP concentrations are in general an order of magnitude higher, with a median concentration of $3.8 \mathrm{std} \mathrm{L}^{-1}$ for winters 2015 and 2016 (HINC) and $2.2 \mathrm{stdL}^{-1}$ during winter 2014 (Boose et al., 2016a). Differences in INP concentrations from year to year are expected to occur due to natural variability.

In winter 2015, an increase in INP concentrations above water saturation was observed during the influence of an air mass of marine origin, with up to $72.1 \mathrm{std} \mathrm{L}^{-1}$ and a median concentration of $16.3 \mathrm{std} \mathrm{L}^{-1}$. The support of marine influence was based on chemical analysis of cloud water samples with a high $f(\mathrm{Sr})_{\mathrm{ss}}$ and an increased $\mathrm{Na} / \mathrm{Al}$ ratio. Model calculations of back trajectories and air mass origin further support our conclusion of a marine source but cannot exclude contributions from anthropogenic or other sources due to entrained particles, which can result in chemical ageing processes during transport to the JFJ. Another marine event was identified in winter 2016, when INP concentrations increased to values up to $176.8 \mathrm{std} \mathrm{L}^{-1}$. During winter 2014, Boose et al. (2016a) identified a marine influenced air mass arriving at the JFJ, but the INP concentrations were within the campaign average. Our findings suggest that the JFJ could regularly be affected by marine aerosols, which can therefore contribute to bursts of increased INP populations in the FT.

An air mass with an increase of INPs was sampled during a SDE in winter 2015, with median INP concentrations reaching $42.6 \mathrm{stdL}^{-1}$ and a peak INP concentration of $146.2 \mathrm{std} \mathrm{L}^{-1}$. The identification of the dust-laden air 
mass was supported by several independent measures of aerosol physical and optical properties such as an increase in larger-sized particles $(0.4-0.8$ and $>0.8 \mu \mathrm{m})$, a negative SSA Ångström exponent, chemical analysis of cloud water samples and a decrease in the $\mathrm{Na} / \mathrm{Al}$ and $\mathrm{Pb} / \mathrm{Al}$ ratios due to an enrichment in Al. The dust source was further supported by air mass back-trajectory and source sensitivity calculations, revealing the Sahara as a source region.

To extend measurements to warmer temperatures, a significantly improved LOD must be achieved as INP are rarer. To quantify INP concentrations in the range between 253 and $273 \mathrm{~K}$, a technique that is sensitive at warmer temperatures must be used, such as offline techniques of drop freezing (e.g., Mason et al., 2015; Conen et al., 2015). However, improving the LOD of online counters can also be achieved by means of using an aerosol concentrator upstream of an INP counter. This has been done in winters 2013 and 2014 (Boose et al., 2016a), achieving a concentration factor of 3 . Recently a more efficient aerosol concentrator was implemented during a field campaign at the JFJ (winter 2017) and will be the subject of a separate study. The ability to conduct field measurements with HINC will aid future measurements with increasing frequency at the JFJ to determine diurnal and interannual variabilities in INP concentrations at this location.

Data availability. INP measurements and data on air mass an aerosol properties are available online at: https://doi.org/10.3929/ ethz-b-000207415. 
Appendix A: Residence time experiments for $242 \mathrm{~K}$ and $104 \% \mathbf{R H}_{\mathbf{w}}$

The optimum residence time for the ice crystal detection at the conditions used in the field experiments was determined by using $400 \mathrm{~nm}$ microcline particles which are INPs at this temperature (e.g., Atkinson et al., 2013a). The position of the aerosol injector and thus the residence time was chosen accordingly, and the AF of the ice crystal concentration in the OPC size channel $>5 \mu \mathrm{m}$ was determined (Fig. A1). The tests revealed the maximum $\mathrm{AF}$ at $8 \mathrm{~s}$ residence time, which gives the aerosols enough time to activate into ice crystals and grow to sizes $>5 \mu \mathrm{m}$, at the same time preventing gravitational settling losses.

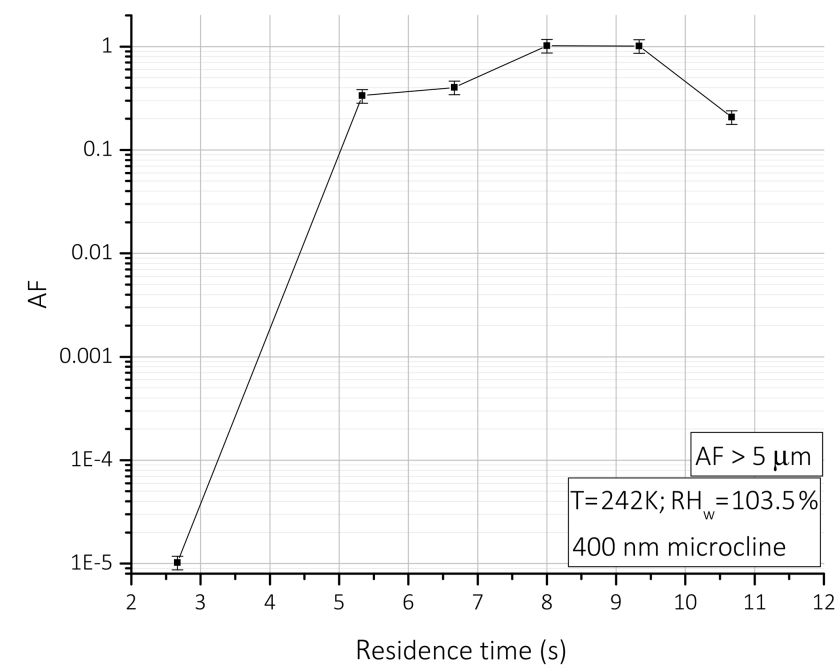

Figure A1. AF as function of residence time for $400 \mathrm{~nm}$ microcline particles at $242 \mathrm{~K}$ and $\mathrm{RH}_{\mathrm{W}}=104 \%$; data are the average over a total of three experiments at each residence time. 


\section{Appendix B: Meteorological conditions}

For a complete description of the INP measurements in winter 2015 the meteorological data during the same sampling period are presented in Fig. B1.

Ambient temperatures $\left(T_{\text {ambient }}\right)$ stayed below $0{ }^{\circ} \mathrm{C}$ for the whole campaign duration, ranging between -9 and $-24^{\circ} \mathrm{C}$ (Fig. B1b). The sky temperature $\left(T_{\text {sky }}\right)$ is calculated from the long-wave radiation measured at the site, and is used to discriminate between in-cloud and out-of-cloud conditions (see Herrmann et al., 2015). During times when the site is in clouds, one would expect the difference between $T_{\text {ambient }}$ and $T_{\text {sky }}$ to be small, since the long-wave radiation received presents the temperature of the cloud surrounding the site and having a similar temperature as the ambient air. INP measurements in- and out-of-cloud conditions do not show significant differences.
The wind velocity (windv) as well as the hourly maximum wind velocity also do not show a correlation with INP concentrations, and a relationship between them is excluded (Fig. B1c), also excluding the role of blowing snow (Lloyd et al., 2015) in our measurements. The wind direction at the JFJ (Fig. B1d) represents the two typical wind directions from northwest and southeast, which is a result of the orientation of the surrounding terrain. The SDE on 6 February was transported in a southeasterly flow, as expected, despite no relation to INP concentration can be concluded. Also, the ambient RH does not show an influence on INP concentrations (Fig. B1e).

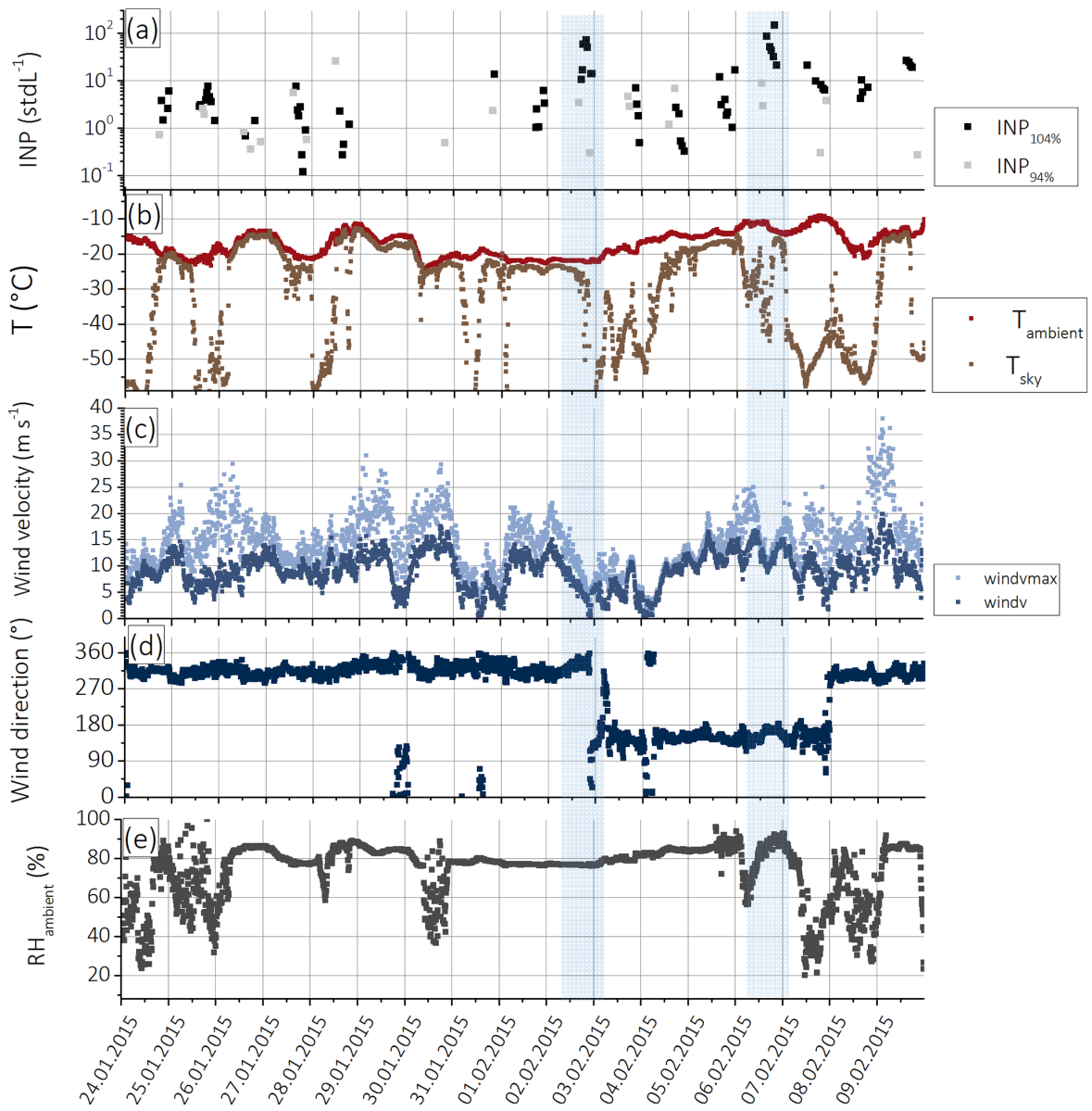

Figure B1. Time series of meteorological data, taken by MeteoSwiss: (a) INP concentrations at $242 \mathrm{~K}$ and $\mathrm{RH}_{\mathrm{W}}=104$ and $94 \%$ as measured with HINC; (b) ambient temperature $\left(T_{\text {ambient }}\right)$ and sky temperature $\left(T_{\text {sky }}\right)$ (Herrmann et al., 2015); (c) hourly maximum wind velocity (windmax) and wind velocity (windv); (d) wind direction; (e) ambient relative humidity $\left(\mathrm{RH}_{\text {ambient }}\right)$. 
Appendix C: Back-trajectory and source emission sensitivities for 3 February 2015

During 3 February 2015 an increase in aerosol particles $>0.5 \mu \mathrm{m}$ was observed, which did not lead to an increase in INP concentrations below and above water saturation. To exclude influence of Saharan dust particles, which is also indicated in an increase in larger particles, we show here source emission sensitivities (Fig. C1a) and back trajectories (Fig. C1b) for the respective day, which indicate the air mass arriving at the JFJ originated in northern Europe and therefore exclude the Sahara as a source region.
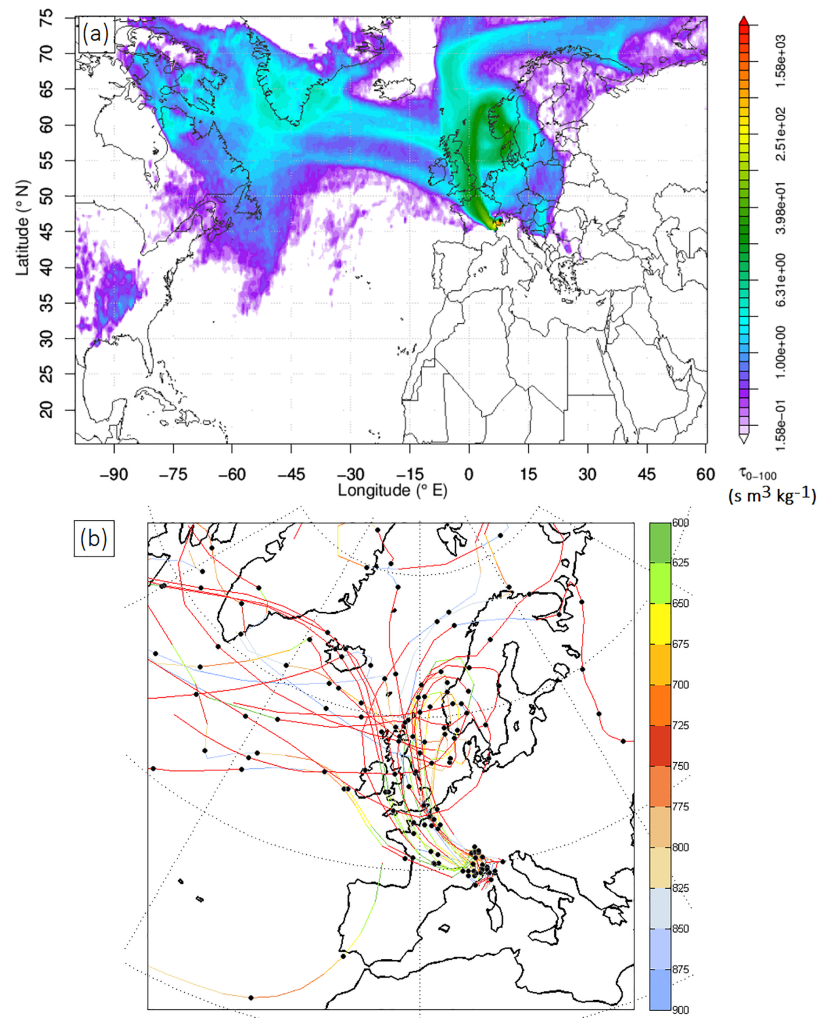

Figure C1. (a) FLEXPART emission sensitivity fields for 3 February 2015 calculated $100 \mathrm{~m}$ above model ground level (http:// lagrange.empa.ch/FLEXPART_browser/; Stohl et al., 2005; Sturm et al., 2013; Pandey Deolal et al., 2014), color code represents the strength of source region contributions to the aerosol burden given in a unit flux per area. (b) Ten-day back trajectories calculated with LAGRANTO (Wernli and Davies, 1997); the color code represents the trajectory pressure above model ground, and black points indicate each $24 \mathrm{~h}$ back calculation. 
Author contributions. LL wrote the manuscript, with contributions from ZAK. ZAK and UL conceived the field study. ZAK and LL designed the laboratory experiments. Field measurements were designed by LL, YB and ZAK. LL conducted all INP measurements and analyzed all INP data. LL, ZAK and UL interpreted the INP data. AZ conducted part of the cloud water sampling, and analyzed and interpreted all the data. EH contributed data on size distributions. NB contributed data on absorption characteristics. MS contributed data on trace gases. ZAK oversaw the overall project.

Competing interests. The authors declare that they have no conflict of interest.

Special issue statement. This article is part of the special issue "BACCHUS - Impact of Biogenic versus Anthropogenic emissions on Clouds and Climate: towards a Holistic UnderStanding (ACP/AMT/GMD inter-journal SI)". It is not associated with a conference.

Acknowledgements. This research was funded by the Global Atmospheric Watch, Switzerland (MeteoSwiss GAW-CH+ 2014-2017). We thank the International Foundation High Altitude Research Station Jungfraujoch and Gornergrat (HFJG) for the opportunity to perform the measurements, and the custodians Maria and Urs Otz, Joan and Martin Fischer, Susanne and Felix Seiler for their support and help. For providing meteorological data we thank MeteoSwiss. Yvonne Boose and Ulrike Lohmann acknowledge funding from the European Union's Seventh Framework Programme (FP7/20072013) under grant agreement no. 603445 (BACCHUS). Trace gases measured at the JFJ are part of the Swiss National Air Pollution Monitoring Network, which is jointly run by EMPA and the Swiss Federal Office for the Environment. This project has also received funding from the European Union's Horizon 2020 research and innovation program under grant agreement no. 654109 as well as the Swiss State Secretariat for Education, Research and Innovation (SERI) under contract no. 15.0159-1. The opinions expressed and arguments employed herein do not necessarily reflect the official views of the Swiss Government. We acknowledge James Atkinson, Robert David, Fabian Mahrt, Franz Friebel, Nadine Borduas and Claudia Marcolli for useful discussions. For technical support we would like to thank Hannes Wydler, whose expertise greatly helped to improve the instrument.

Edited by: Markus Petters

Reviewed by: three anonymous referees

\section{References}

Aller, J. Y., Kuznetsova, M. R., Jahns, C. J., and Kemp, P. F.: The sea surface microlayer as a source of viral and bacterial enrichment in marine aerosols, J. Aerosol Sci., 36, 801-812, https://doi.org/10.1016/j.jaerosci.2004.10.012, 2005.

Alpert, P. A., Aller, J. Y., and Knopf, D. A.: Initiation of the ice phase by marine biogenic surfaces in supersaturated gas and supercooled aqueous phases, Phys. Chem. Chem. Phys., 13, 19882-19894, https://doi.org/10.1039/c1cp21844a, 2011.

Ansmann, A., Tesche, M., Althausen, D., Muller, D., Seifert, P., Freudenthaler, V., Heese, B., Wiegner, M., Pisani, G., Knippertz, P., and Dubovik, O.: Influence of Saharan dust on cloud glaciation in southern Morocco during the Saharan Mineral Dust Experiment, J. Geophys. Res.-Atmos., 113, D04210, https://doi.org/10.1029/2007jd008785, 2008.

Appenzeller, C., Begert, M., Zenklusen, E., and Scherrer, S. C.: Monitoring climate at Jungfraujoch in the high Swiss Alpine region, Sci. Total Environ., 391, 262-268, https://doi.org/10.1016/j.scitotenv.2007.10.005, 2008.

Ardon-Dryer, K. and Levin, Z.: Ground-based measurements of immersion freezing in the eastern Mediterranean, Atmos. Chem. Phys., 14, 5217-5231, https://doi.org/10.5194/acp-145217-2014, 2014.

Ardon-Dryer, K., Garimella, S., Huang, Y. W., Christopoulos, C., and Cziczo, D. J.: Evaluation of DMA size selection of dry dispersed mineral dust particles, Aerosol Sci. Tech., 49, 828-841, https://doi.org/10.1080/02786826.2015.1077927, 2015.

Atkinson, J. D., Murray, B. J., Woodhouse, M. T., Whale, T. F., Baustian, K. J., Carslaw, K. S., Dobbie, S., O'Sullivan, D., and Malkin, T. L.: The importance of feldspar for ice nucleation by mineral dust in mixed-phase clouds, Nature, 498, 355-358, https://doi.org/10.1038/nature12278, 2013a.

Atkinson, J. D., Murray, B. J., Woodhouse, M. T., Whale, T. F., Baustian, K. J., Carslaw, K. S., Dobbie, S., O'Sullivan, D., and Malkin, T. L.: The importance of feldspar for ice nucleation by mineral dust in mixed-phase clouds, Nature, 498, 355-358, https://doi.org/10.1038/nature12384, 2013b.

Augustin, S., Wex, H., Niedermeier, D., Pummer, B., Grothe, H., Hartmann, S., Tomsche, L., Clauss, T., Voigtländer, J., Ignatius, K., and Stratmann, F.: Immersion freezing of birch pollen washing water, Atmos. Chem. Phys., 13, 10989-11003, https://doi.org/10.5194/acp-13-10989-2013, 2013.

Avramov, A., Ackerman, A. S., Fridlind, A. M., van Diedenhoven, B., Botta, G., Aydin, K., Verlinde, J., Korolev, A. V., Strapp, J. W., McFarquhar, G. M., Jackson, R., Brooks, S. D., Glen, A., and Wolde, M.: Toward ice formation closure in Arctic mixed-phase boundary layer clouds during ISDAC, J. Geophys. Res.-Atmos., 116, D00T08, https://doi.org/10.1029/2011JD015910, 2011.

Baltensperger, U., Gäggeler, H. W., Jost, D. T., Lugauer, M., Schwikowski, M., Weingartner, E., and Seibert, P.: Aerosol climatology at the high-alpine site Jungfraujoch, Switzerland, J. Geophys. Res., 102, 19707-719715, https://doi.org/10.1029/97JD00928, 1997.

Baltensperger, U., Schwikowski, M., Jost, D. T., Nyeki, S., Gäggeler, H. W., and Poulida, O.: Scavenging of atmospheric constituents in mixed phase clouds at the highalpine site jungfraujoch part I: Basic concept and aerosol scavenging by clouds, Atmos. Environ., 32, 3975-3983, https://doi.org/10.1016/S1352-2310(98)00051-X, 1998.

Bigg, E. K.: Cross sections of ice nucleus concentrations at altitude over long paths, J. Atmos. Sci., 24, 226-229, https://doi.org/10.1175/15200469(1967)024<0226:CSOINC>2.0.CO;2, 1967.

Bingemer, H., Klein, H., Ebert, M., Haunold, W., Bundke, U., Herrmann, T., Kandler, K., Müller-Ebert, D., Weinbruch, S., 
Judt, A., Wéber, A., Nillius, B., Ardon-Dryer, K., Levin, Z., and Curtius, J.: Atmospheric ice nuclei in the Eyjafjallajökull volcanic ash plume, Atmos. Chem. Phys., 12, 857-867, https://doi.org/10.5194/acp-12-857-2012, 2012.

Bode, A. A. C., Pulles, P. G. M., Lutz, M., Poulisse, W. J. M., Jiang, S., Meijer, J. A. M., van Enckevort, W. J. P., and Vlieg, E.: Sodium Chloride Dihydrate Crystals: Morphology, Nucleation, Growth, and Inhibition, Cryst. Growth Des., 15, 3166-3174, https://doi.org/10.1021/acs.cgd.5b00061, 2015.

Boose, Y., Kanji, Z. A., Kohn, M., Sierau, B., Zipori, A., Crawford, I., Lloyd, G., Bukowiecki, N., Herrmann, E., Kupiszewski, P., Steinbacher, M., and Lohmann, U.: Ice nucleating particle measurements at $241 \mathrm{~K}$ during winter months at $3580 \mathrm{~m}$ MSL in the Swiss Alps, J. Atmos. Sci., 73, 2203-2228, https://doi.org/10.1175/JAS-D-15-0236.1, 2016a.

Boose, Y., Sierau, B., García, M. I., Rodríguez, S., Alastuey, A., Linke, C., Schnaiter, M., Kupiszewski, P., Kanji, Z. A., and Lohmann, U.: Ice nucleating particles in the Saharan Air Layer, Atmos. Chem. Phys., 16, 9067-9087, https://doi.org/10.5194/acp-16-9067-2016, 2016b.

Boucher, O., Randall, D., Artaxo, P., Bretherton, C., Feingold, G., Forster, P., Kerminen, V.-M., Kondo, Y., Liao, H., Lohmann, U., Rasch, P., Satheesh, S. K., Sherwood, S., Stevens, B., and Zhang, X. Y.: Clouds and aerosols, in: Climate Change 2013: The Physical Science Basis, Contribution of Working Group I to the Fifth Assessment Report of the Intergovernmental Panel on Climate Change, edited by: Stocker, T. F., Qin, D., Plattner, G.K., Tignor, M., Allen, S. K., Boschung, J., Nauels, A., Xia, Y., Bex, V., and Midgley, P. M., Cambridge University Press, Cambridge, UK and New York, NY, USA, 571-658, 2013.

Brier, G. W. and Kline, D. B.: Ocean water as a source for ice nuclei, Science, 130, 717-718, https://doi.org/10.1126/science.130.3377.717, 1959.

Bukowiecki, N., Weingartner, E., Gysel, M., Collaud Coen, M., Zieger, P., Herrmann, E., Steinbacher, M., Gäggeler, H. W., and Baltensperger, U.: A review of more than 20 years of Aerosol Observation at the high altitude research station Jungfraujoch, Switzerland (3580 ma.s.1.), Aerosol Air Qual. Res., 16, 764-788, https://doi.org/10.4209/aaqr.2015.05.0305, 2016.

Burkert-Kohn, M., Wex, H., Welti, A., Hartmann, S., Grawe, S., Hellner, L., Herenz, P., Atkinson, J. D., Stratmann, F., and Kanji, Z. A.: Leipzig Ice Nucleation chamber Comparison (LINC): intercomparison of four online ice nucleation counters, Atmos. Chem. Phys., 17, 11683-11705, https://doi.org/10.5194/acp-1711683-2017, 2017.

Burrows, S. M., Hoose, C., Pöschl, U., and Lawrence, M. G.: Ice nuclei in marine air: biogenic particles or dust?, Atmos. Chem. Phys., 13, 245-267, https://doi.org/10.5194/acp-13-2452013, 2013.

Capo, R. C., Stewart, B. W., and Chadwick, O. A.: Strontium isotopes as tracers of ecosystem processes: theory and methods, Geoderma, 82, 197-225, https://doi.org/10.1016/S00167061(97)00102-X, 1998.

Chou, C., Stetzer, O., Weingartner, E., Jurányi, Z., Kanji, Z. A., and Lohmann, U.: Ice nuclei properties within a Saharan dust event at the Jungfraujoch in the Swiss Alps, Atmos. Chem. Phys., 11, 4725-4738, https://doi.org/10.5194/acp-11-4725-2011, 2011.

Collaud Coen, M., Weingartner, E., Schaub, D., Hueglin, C., Corrigan, C., Henning, S., Schwikowski, M., and Baltensperger,
U.: Saharan dust events at the Jungfraujoch: detection by wavelength dependence of the single scattering albedo and first climatology analysis, Atmos. Chem. Phys., 4, 2465-2480, https://doi.org/10.5194/acp-4-2465-2004, 2004.

Collaud Coen, M., Weingartner, E., Furger, M., Nyeki, S., Prévôt, A. S. H., Steinbacher, M., and Baltensperger, U.: Aerosol climatology and planetary boundary influence at the Jungfraujoch analyzed by synoptic weather types, Atmos. Chem. Phys., 11, 5931-5944, https://doi.org/10.5194/acp-11-5931-2011, 2011.

Conen, F., Morris, C. E., Leifeld, J., Yakutin, M. V., and Alewell, C.: Biological residues define the ice nucleation properties of soil dust, Atmos. Chem. Phys., 11, 9643-9648, https://doi.org/10.5194/acp-11-9643-2011, 2011.

Conen, F., Rodríguez, S., Hüglin, C., Henne, S., Herrmann, E., Bukowiecki, N., and Alewell, C.: Atmospheric ice nuclei at the high-altitude observatory Jungfraujoch, Switzerland, Tellus B, 67, 25014, https://doi.org/10.3402/tellusb.v67.25014, 2015.

Cunliffe, M., Engel, A., Frka, S., Gašparovic, B., Guitart, C., Murrell, J. C., Salter, M., Stolle, C., UpstillGoddard, R., and Wurl, O.: Sea surface microlayers: a unified physicochemical and biological perspective of the air-ocean interface, Prog. Oceanogr., 109, 104-116, https://doi.org/10.1016/j.pocean.2012.08.004, 2013.

Cziczo, D. J. and Abbatt, J. P. D.: Deliquescence, efflorescence, and supercooling of ammonium sulfate aerosols at low temperature: implications for cirrus cloud formation and aerosol phase in the atmosphere, J. Geophys. Res.-Atmos., 104, 13781-13790, https://doi.org/10.1029/1999JD900112, 1999.

Cziczo, D. J., Froyd, K. D., Hoose, C., Jensen, E. J., Diao, M. H., Zondlo, M. A., Smith, J. B., Twohy, C. H., and Murphy, D. M.: Clarifying the dominant sources and mechanisms of Cirrus Cloud Formation, Science, 340, 1320-1324, https://doi.org/10.1126/science.1234145, 2013.

Cziczo, D. J. and Froyd, K. D.: Sampling the composition of cirrus ice residuals, Atmos. Res., 142, 15-31, https://doi.org/10.1016/j.atmosres.2013.06.012, 2014.

DeLeon-Rodriguez, N., Lathem, T. L., Rodriguez-R, L. M., Barazesh, J. M., Anderson, B. E., Beyersdorf, A. J., Ziemba, L. D., Bergin, M., Nenes, A., and Konstantinidis, K. T.: Microbiome of the upper troposphere: species composition and prevalence, effects of tropical storms, and atmospheric implications, P. Natl. Acad. Sci. USA, 110, 2575-2580, https://doi.org/10.1073/pnas.1212089110, 2013.

DeMott, P. J., Cziczo, D. J., Prenni, A. J., Murphy, D. M., Kreidenweis, S. M., Thomson, D. S., Borys, R., and Rogers, D. C.: Measurements of the concentration and composition of nuclei for cirrus formation, P. Natl. Acad. Sci. USA, 100, 14655-14660, https://doi.org/10.1073/pnas.2532677100, 2003a.

DeMott, P. J., Sassen, K., Poellot, M. R., Baumgardner, D., Rogers, D. C., Brooks, S. D., Prenni, A. J., and Kreidenweis, S. M.: African dust aerosols as atmospheric ice nuclei, Geophys. Res. Lett., 30, L07808, https://doi.org/10.1029/2009GL037639, 2003b.

DeMott, P. J., Prenni, A. J., Liu, X., Kreidenweis, S. M., Petters, M. D. a. T., C. H., Richardson, M. S., Eidhammer, T., and Rogers, D. C.: Predicting global atmospheric ice nuclei distributions and their impacts on climate, P. Natl. Acad. Sci. USA, 107, 11217-11222, https://doi.org/10.1073/pnas.0910818107, 2010. 
DeMott, P. J., Hill, T. C. J., McCluskey, C. S., Prather, K. A., Collins, D. B., Sullivan, R. C., Ruppel, M. J., Mason, R. H., Irish, V. E., Lee, T., Hwang, C. Y., Rhee, T. S., Snider, J. R., McMeeking, G. R., Dhaniyala, S., Lewis, E. R., Wentzell, J. J. B., Abbatt, J., Lee, C., Sultana, C. M., Ault, A. P., Axson, J. L., Diaz Martinez, M., Venero, I., Santos-Figueroa, G., Stokes, M. D., Deane, G. B., Mayol-Bracero, O. L., Grassian, V. H., Bertram, T. H., Bertram, A. K., Moffett, B. F., and Franc, G. D.: Sea spray aerosol as a unique source of ice nucleating particles, P. Natl. Acad. Sci. USA, 113, 5797-5803, https://doi.org/10.1073/pnas.1514034112, 2016.

Després, V., Huffman, J., Burrows, S., Hoose, C., Safatov, A., Buryak, G., Fröhlich-Nowoisky, J., Elbert, W., Andreae, M., Pöschl, U., and Jaenicke, R.: Primary biological aerosol particles in the atmosphere: a review, Tellus B, 64, 15598, https://doi.org/10.3402/tellusb.v64i0.15598, 2012.

Fröhlich-Nowoisky, J., Hill, T. C. J., Pummer, B. G., Yordanova, P., Franc, G. D., and Pöschl, U.: Ice nucleation activity in the widespread soil fungus Mortierella alpina, Biogeosciences, 12, 1057-1071, https://doi.org/10.5194/bg-12-1057-2015, 2015.

Gantt, B. and Meskhidze, N.: The physical and chemical characteristics of marine primary organic aerosol: a review, Atmos. Chem. Phys., 13, 3979-3996, https://doi.org/10.5194/acp13-3979-2013, 2013.

Griffiths, A. D., Parkes, S. D., Chambers, S. D., McCabe, M. F., and Williams, A. G.: Improved mixing height monitoring through a combination of lidar and radon measurements, Atmos. Meas. Tech., 6, 207-218, https://doi.org/10.5194/amt-6207-2013, 2013.

Griffiths, A. D., Conen, F., Weingartner, E., Zimmermann, L., Chambers, S. D., Williams, A. G., and Steinbacher, M.: Surfaceto-mountaintop transport characterised by radon observations at the Jungfraujoch, Atmos. Chem. Phys., 14, 12763-12779, https://doi.org/10.5194/acp-14-12763-2014, 2014.

Harrison, A. D., Whale, T. F., Carpenter, M. A., Holden, M. A., Neve, L., O'Sullivan, D., Vergara Temprado, J., and Murray, B. J.: Not all feldspars are equal: a survey of ice nucleating properties across the feldspar group of minerals, Atmos. Chem. Phys., 16, 10927-10940, https://doi.org/10.5194/acp-16-109272016, 2016.

Herrmann, E., Weingartner, E., Henne, S., Vuilleumier, L., Bukowiecki, N., Steinbacher, M., Conen, F., Collaud Coen, M., Hammer, E., Jurányi, Z., Baltensperger, U., and Gysel, M.: Analysis of long-term aerosol size distribution data from Jungfraujoch with emphasis on free tropospheric conditions, cloud influence, and air mass transport, J. Geophys. Res.-Atmos., 120, 9459-9480, https://doi.org/10.1002/2015JD023660, 2015.

Herut, B., Starinsky, A., and Katz, A.: Strontium in rainwater from Israel: sources, isotopes and chemistry, Earth Planet. Sc. Lett., 120, 77-84, https://doi.org/10.1016/0012-821X(93)900244, 1993.

Hodell, D. A., Mead, G. A., and Mueller, P. A.: Variation in the strontium isotopic composition of seawater (8 Ma to present): implications for chemical weathering rates and dissolved fluxes to the oceans, Chem. Geol., 80, 291-307, https://doi.org/10.1016/0168-9622(90)90011-Z, 1990.

Hoose, C. and Möhler, O.: Heterogeneous ice nucleation on atmospheric aerosols: a review of results from labo- ratory experiments, Atmos. Chem. Phys., 12, 9817-9854, https://doi.org/10.5194/acp-12-9817-2012, 2012.

Kamphus, M., Ettner-Mahl, M., Klimach, T., Drewnick, F., Keller, L., Cziczo, D. J., Mertes, S., Borrmann, S., and Curtius, J.: Chemical composition of ambient aerosol, ice residues and cloud droplet residues in mixed-phase clouds: single particle analysis during the Cloud and Aerosol Characterization Experiment (CLACE 6), Atmos. Chem. Phys., 10, 8077-8095, https://doi.org/10.5194/acp-10-8077-2010, 2010.

Kanji, Z. A. and Abbatt, J. P. D.: The University of Toronto Continuous Flow Diffusion Chamber (UT-CFDC): a simple design for ice nucleation studies, Aerosol Sci. Tech., 43, 730-738, https://doi.org/10.1080/02786820902889861, 2009.

Kanji, Z. A., Ladino, L. A., Wex, H., Boose, Y., BurkertKohn, M., Cziczo, D. J., and Krämer, M.: Chapter 1: overview of ice nucleating particles, Meteor. Mon., 58, 1.1-1.33, https://doi.org/10.1175/amsmonographs-d-16-0006.1, 2017.

Kaufmann, L., Marcolli, C., Hofer, J., Pinti, V., Hoyle, C. R., and Peter, T.: Ice nucleation efficiency of natural dust samples in the immersion mode, Atmos. Chem. Phys., 16, 11177-11206, https://doi.org/10.5194/acp-16-11177-2016, 2016.

Knopf, D. A., Alpert, P. A., Wang, B., and Aller, J. Y.: Stimulation of ice nucleation by marine diatoms, Nat. Geosci., 4, 88-90, https://doi.org/10.1038/NGEO1037, 2011.

Knopf, D. A., Alpert, P. A., Wang, B., O'Brien, R. E., Kelly, S. T., Laskin, A., Gilles, M. K., and Moffet, R. C.: Microspectroscopic imaging and characterization of individually identified ice nucleating particles from a case field study, J. Geophys. Res.-Atmos., 119, 10365-10381, https://doi.org/10.1002/2014JD021866, 2014.

Koop, T., Luo, B., Tsias, A., and Peter, T.: Water activity as the determinant for homogeneous ice nucleation in aqueous solutions, Nature, 406, 611-614, https://doi.org/10.1038/35020537, 2000a.

Koop, T., Kapilashrami, A., Molina, L. T., and Molina, M. J.: Phase transitions of sea-salt/water mixtures at low temperatures: implications for ozone chemistry in the polar marine boundary layer, J. Geophys. Res.-Atmos., 105, 26393-26402, https://doi.org/10.1029/2000JD900413, 2000 b.

Ladino, L. A., Yakobi-Hancock, J. D., Kilthau, W. P., Mason, R. H., Si, M., Li, J., Miller, L. A., Schiller, C. L., Huffman, J. A., Aller, J. Y., Knopf, D. A., Bertram, A. K., and Abbatt, J. P. D.: Addressing the ice nucleating abilities of marine aerosol: a combination of deposition mode laboratory and field measurements, Atmos. Environ., 132, 1-10, https://doi.org/10.1016/j.atmosenv.2016.02.028, 2016.

de Leeuw, G., Andreas, E. L., Anguelova, M. D., Fairall, C. W., Lewis, E. R., O'Dowd, C., Schulz, M., and Schwartz, S. E.: Production flux of sea spray aerosol, Rev. Geophys., 49, RG2001, https://doi.org/10.1029/2010RG000349, 2011.

Lloyd, G., Choularton, T. W., Bower, K. N., Gallagher, M. W., Connolly, P. J., Flynn, M., Farrington, R., Crosier, J., Schlenczek, O., Fugal, J., and Henneberger, J.: The origins of ice crystals measured in mixed-phase clouds at the highalpine site Jungfraujoch, Atmos. Chem. Phys., 15, 12953-12969, https://doi.org/10.5194/acp-15-12953-2015, 2015.

Lohmann, U., Lüönd, F., and Mahrt, F.: An Introduction to Clouds: from the Microscale to Climate, Cambridge University Press, Cambridge, 2016. 
Lugauer, M., Baltensperger, U., Furger, M., Gäggeler, H. W., Jost, D. T., Schwikowski, M., and Wanner, H.: Aerosol transport to the high Alpine sites Jungfraujoch (3454 ma.s.1.) and Colle Gnifetti (4452 ma.s.1.), Tellus B, 50, 76-92, https://doi.org/10.1034/j.1600-0889.1998.00006.x, 1998.

Mason, R. H., Chou, C., McCluskey, C. S., Levin, E. J. T., Schiller, C. L., Hill, T. C. J., Huffman, J. A., DeMott, P. J., and Bertram, A. K.: The micro-orifice uniform deposit impactordroplet freezing technique (MOUDI-DFT) for measuring concentrations of ice nucleating particles as a function of size: improvements and initial validation, Atmos. Meas. Tech., 8, 24492462, https://doi.org/10.5194/amt-8-2449-2015, 2015.

Mason, R. H., Si, M., Chou, C., Irish, V. E., Dickie, R., Elizondo, P., Wong, R., Brintnell, M., Elsasser, M., Lassar, W. M., Pierce, K. M., Leaitch, W. R., MacDonald, A. M., Platt, A., ToomSauntry, D., Sarda-Estève, R., Schiller, C. L., Suski, K. J., Hill, T. C. J., Abbatt, J. P. D., Huffman, J. A., DeMott, P. J., and Bertram, A. K.: Size-resolved measurements of ice-nucleating particles at six locations in North America and one in Europe, Atmos. Chem. Phys., 16, 1637-1651, https://doi.org/10.5194/acp16-1637-2016, 2016.

Meola, M., Lazzaro, A., and Zeyer, J.: Bacterial composition and survival on Sahara dust particles transported to the European Alps, Front. Microbiol., 6, 1454, https://doi.org/10.3389/fmicb.2015.01454, 2015.

Murray, B. J., O'Sullivan, D., Atkinson, J. D., and Webb, M. E.: Ice nucleation by particles immersed in supercooled cloud droplets, Chem. Soc. Rev., 41, 6519-6554, https://doi.org/10.1039/C2CS35200A, 2012.

Nyeki, S., Li, F., Weingartner, E., Streit, N., Colbeck, I., Gäggeler, H. W., and Baltensperger, U.: The background aerosol size distribution in the free troposphere: an analysis of the annual cycle at a high-alpine site, J. Geophys. Res., 103, 31749-31761, https://doi.org/10.1029/1998JD200029, 1998.

O'Sullivan, D., Murray, B. J., Ross, J. F., Whale, T. F., Price, H. C., Atkinson, J. D., Umo, N. S., and Webb, M. E.: The relevance of nanoscale biological fragments for ice nucleation in clouds, Sci. Rep.-UK, 5, 8082, https://doi.org/10.1038/srep08082, 2015.

Pandey Deolal, S., Staehelin, J., Brunner, D., Cui, J., Steinbacher, M., Zellweger, C., Henne, S., and Vollmer, M. K.: Transport of PAN and $\mathrm{NO}_{y}$ from different source regions to the Swiss high alpine site Jungfraujoch, Atmos. Environ., 64, 103-115, https://doi.org/10.1016/j.atmosenv.2012.08.021, 2013.

Pandey Deolal, S., Henne, S., Ries, L., Gilge, S., Weers, U., Steinbacher, M., Staehelin, J., and Peter, T.: Analysis of elevated springtime levels of Peroxyacetyl nitrate (PAN) at the high Alpine research sites Jungfraujoch and Zugspitze, Atmos. Chem. Phys., 14, 12553-12571, https://doi.org/10.5194/acp-14-125532014, 2014.

Prather, K. A., Bertram, T. H., Grassian, V. H., Deane, G. B., Stokes, M. D., DeMott, P. J., Aluwihare, L. I., Palenik, B. P., Azam, F., Seinfeld, J. H., Moffet, R. C., Molina, M. J., Cappa, C. D., Geiger, F. M., Roberts, G. C., Russell, L. M., Ault, A. P., Baltrusaitis, J., Collins, D. B., Corrigan, C. E., Cuadra-Rodriguez, L. A., Ebben, C. J., Forestieri, S. D., Guasco, T. L., Hersey, S. P., Kim, M. J., Lambert, W. F., Modini, R. L., Mui, W., Pedler, B. E., Ruppel, M. J., Ryder, O. S., Schoepp, N. G., Sullivan, R. C., and Zhao, D.: Bringing the ocean into the laboratory to probe the chemical complexity of sea spray aerosol, P. Natl. Acad. Sci. USA, 110, 7550-7555, 2013.

Prenni, A., DeMott, P., Rogers, D., Kreidenweis, S. M., McFarquhar, G. M., Zhang, G., and Poellot, M. R.: Ice nuclei characteristics from M-PACE and their relation to ice formation in clouds, Tellus B, 61, 436-448, https://doi.org/10.1111/j.16000889.2009.00415.x, 2009.

Pruppacher, H. R. and Klett, J. D.: Microphysics of Clouds and Precipitation, Kluwer Acad., Norwell, Mass, 1997.

Pummer, B. G., Bauer, H., Bernardi, J., Bleicher, S., and Grothe, H.: Suspendable macromolecules are responsible for ice nucleation activity of birch and conifer pollen, Atmos. Chem. Phys., 12, 2541-2550, https://doi.org/10.5194/acp-12-2541-2012, 2012.

Rogers, D. C.: Development of a continuous flow thermal gradient diffusion chamber for ice nucleation studies, Atmos. Res., 22 149-181, https://doi.org/10.1016/0169-8095(88)90005-1, 1988.

Rogers, D. C., DeMott, P. J., Kreidenweis, S. M., and Chen, Y.: Measurements of ice nucleating aerosols during SUCCESS, Geophys. Res. Lett., 25, 1383-1386, https://doi.org/10.1029/97GL03478, 1998.

Rogers, D. C., DeMott, P. J., Kreidenweis, S. M., and Chen, Y.: A continuous-flow diffusion chamber for airborne measurements of ice nuclei, J. Atmos. Ocean. Tech., 18, 725-741, https://doi.org/10.1175/15200426(2001)018<0725:ACFDCF>2.0.CO;2, 2001.

Rogers, R. R. and Yau, M. K.: A Short Course in Cloud Physics, Pergamon, Oxford, 1989.

Santachiara, G., Matteo, L. D., Prodi, F., and Belosi, F.: Atmospheric particles acting as ice forming nuclei in different size ranges, Atmos. Res., 96, 266-272, https://doi.org/10.1016/j.atmosres.2009.08.004, 2010.

Schrod, J., Weber, D., Drücke, J., Keleshis, C., Pikridas, M., Ebert, M., Cvetković, B., Nickovic, S., Marinou, E., Baars, H., Ansmann, A., Vrekoussis, M., Mihalopoulos, N., Sciare, J., Curtius, J., and Bingemer, H. G.: Ice nucleating particles over the Eastern Mediterranean measured by unmanned aircraft systems, Atmos. Chem. Phys., 17, 4817-4835, https://doi.org/10.5194/acp17-4817-2017, 2017.

Sjogren, S., Gysel, M., Weingartner, E., Alfarra, M. R., Duplissy, J., Cozic, J., Crosier, J., Coe, H., and Baltensperger, U.: Hygroscopicity of the submicrometer aerosol at the high-alpine site Jungfraujoch, 3580 ma.s.l., Switzerland, Atmos. Chem. Phys., 8, 5715-5729, https://doi.org/10.5194/acp-8-5715-2008, 2008.

Stein, M., Starinsky, A., Katz, A., Goldstein, S. L., Machlus, M., and Schramm, A.: Strontium isotopic, chemical, and sedimentological evidence for the evolution of Lake Lisan and the Dead Sea, Geochim. Cosmochim. Ac., 61, 3975-3992, https://doi.org/10.1016/S0016-7037(97)00191-9, 1997.

Steinbacher, M., Wyss, S., Emmenegger, L., and Hüglin, C.: National Air Pollution Monitoring Network (NABEL), annual report, International Foundation HFJG, available at: https://www hfsjg.ch/wordpress/reports/2016/118_Empa_Hueglin.pdf, 2016.

Stohl, A., Forster, C., Frank, A., Seibert, P., and Wotawa, G.: Technical note: The Lagrangian particle dispersion model FLEXPART version 6.2, Atmos. Chem. Phys., 5, 2461-2474, https://doi.org/10.5194/acp-5-2461-2005, 2005.

Stopelli, E., Conen, F., Morris, C. E., Herrmann, E., Bukowiecki, N., and Alewell, C.: Ice nucleation active par- 
ticles are efficiently removed by precipitating clouds, Sci. Rep., 5, 16433, https://doi.org/10.1038/srep16433, 2015.

Sturm, P., Tuzson, B., Henne, S., and Emmenegger, L.: Tracking isotopic signatures of $\mathrm{CO}_{2}$ at the high altitude site Jungfraujoch with laser spectroscopy: analytical improvements and representative results, Atmos. Meas. Tech., 6, 1659-1671, https://doi.org/10.5194/amt-6-1659-2013, 2013.

Vali, G., DeMott, P. J., Möhler, O., and Whale, T. F.: Technical Note: A proposal for ice nucleation terminology, Atmos. Chem. Phys., 15, 10263-10270, https://doi.org/10.5194/acp-15-102632015, 2015.

Vergara-Temprado, J., Murray, B. J., Wilson, T. W., O'Sullivan, D., Browse, J., Pringle, K. J., Ardon-Dryer, K., Bertram, A. K., Burrows, S. M., Ceburnis, D., DeMott, P. J., Mason, R. H., O'Dowd, C. D., Rinaldi, M., and Carslaw, K. S.: Contribution of feldspar and marine organic aerosols to global ice nucleating particle concentrations, Atmos. Chem. Phys., 17, 3637-3658, https://doi.org/10.5194/acp-17-3637-2017, 2017.

von der Weiden, S.-L., Drewnick, F., and Borrmann, S.: Particle Loss Calculator - a new software tool for the assessment of the performance of aerosol inlet systems, Atmos. Meas. Tech., 2, 479-494, https://doi.org/10.5194/amt-2-479-2009, 2009.

Weingartner, E., Nyeki, S., and Baltensperger, U.: Seasonal and diurnal variation of aerosol size distributions $(10<\mathrm{D}<750 \mathrm{~nm})$ at a high-alpine site (Jungfraujoch 3580 ma.s.1.), J. Geophys. Res., 104, 26809-26820, https://doi.org/10.1029/1999JD900170, 1999.

Welti, A., Kanji, Z. A., Lüönd, F., Stetzer, O., and Lohmann, U.: Exploring the mechanisms of ice nucleation on kaolinite: from deposition nucleation to condensation freezing, J. Atmos. Sci., 71, 16-36, https://doi.org/10.1175/JAS-D-12-0252.1, 2014.

Wernli, B. H. and Davies, H. C.: A lagrangian-based analysis of extratropical cyclones, I: The method and some applications, Q. J. Roy. Meteor. Soc., 123, 467-489, https://doi.org/10.1256/smsqj.53810, 1997.

Wex, H., DeMott, P. J., Tobo, Y., Hartmann, S., Rösch, M., Clauss, T., Tomsche, L., Niedermeier, D., and Stratmann, F.: Kaolinite particles as ice nuclei: learning from the use of different kaolinite samples and different coatings, Atmos. Chem. Phys., 14, 55295546, https://doi.org/10.5194/acp-14-5529-2014, 2014.
Wilson, T. W., Ladino, L. A., Alpert, P. A., Breckels, M. N., Brooks, I. M., Browse, J., Burrows, S. M., Carslaw, K. S., Huffman, J. A., Judd, C., Kilthau, W. P., Mason, R. H., McFiggans, G., Miller, L. A., Najera, J. J., Polishchuk, E., Rae, S., Schiller, C. L., Si, M., Temprado, J. V., Whale, T. F., Wong, J. P. S., Wurl, O., Yakobi-Hancock, J. D., Abbatt, J. P. D., Aller, J. Y., Bertram, A. K., Knopf, D. A., and Murray, B. J.: A marine biogenic source of atmospheric ice-nucleating particles, Nature, 525, 234-238, https://doi.org/10.1038/nature14986, 2015.

Yakobi-Hancock, J. D., Ladino, L. A., and Abbatt, J. P. D.: Feldspar minerals as efficient deposition ice nuclei, Atmos. Chem. Phys., 13, 11175-11185, https://doi.org/10.5194/acp-13-11175-2013, 2013.

Yun, Y. and Penner, J. E.: An evaluation of the potential radiative forcing and climatic impact of marine organic aerosols as heterogeneous ice nuclei, Geophys. Res. Lett., 40, 4121-4126, https://doi.org/10.1002/grl.50794, 2013.

Zanis, P., Ganser, A., Zellweger, C., Henne, S., Steinbacher, M., and Staehelin, J.: Seasonal variability of measured ozone production efficiencies in the lower free troposphere of Central Europe, Atmos. Chem. Phys., 7, 223-236, https://doi.org/10.5194/acp-7223-2007, 2007.

Zellweger, C., Forrer, J., Hofer, P., Nyeki, S., Schwarzenbach, B., Weingartner, E., Ammann, M., and Baltensperger, U.: Partitioning of reactive nitrogen $\left(\mathrm{NO}_{y}\right)$ and dependence on meteorological conditions in the lower free troposphere, Atmos. Chem. Phys., 3, 779-796, https://doi.org/10.5194/acp-3-7792003, 2003.

Zipori, A., Rosenfeld, D., Shpund, J., Steinberg, D. M., and Erel, Y.: Targeting and impacts of AgI cloud seeding based on rain chemical composition and cloud top phase characterization, Atmos. Res., 114-115, 119-130, https://doi.org/10.1016/j.atmosres.2012.05.023, 2012.

Zipori, A., Rosenfeld, D., Tirosh, O., Teutsch, N., and Erel, Y.: Effects of aerosol sources and chemical compositions on cloud drop sizes and glaciation temperatures, J. Geophys. Res.-Atmos., 120, 9653-9669, https://doi.org/10.1002/2015JD023270, 2015.

Zolles, T., Burkart, J., Häusler, T., Pummer, B., Hitzenberger, R., and Grother, H.: Identification of ice nucleation active sites on feldspar dust particles, J. Phys. Chem. A, 119, 2692-2700, https://doi.org/10.1021/jp509839x, 2015. 